\title{
Inhibition of Cytohesins Protects against Genetic Models of Motor Neuron Disease
}

\author{
Jinbin Zhai, ${ }^{1 \star}$ Lei Zhang, ${ }^{1 \star}$ Jelena Mojsilovic-Petrovic, ${ }^{1}$ Xiaoying Jian, ${ }^{5}$ Jeffrey Thomas, ${ }^{2}$ Kengo Homma, ${ }^{7}$ \\ Anton Schmitz, ${ }^{6}$ Michael Famulok, ${ }^{6}$ Hidenori Ichijo, ${ }^{7}$ Yair Argon, ${ }^{2}$ Paul A. Randazzo, ${ }^{5}$ and Robert G. Kalb ${ }^{1,3,4}$ \\ ${ }_{1}^{1}$ Division of Pediatric Neurology and ${ }^{2}$ Division of Cell Pathology, Research Institute, Children's Hospital of Philadelphia, Philadelphia, Pennsylvania 19104, \\ ${ }^{3}$ Department of Neurology and ${ }^{4}$ Department of Pediatrics, Perelman School of Medicine, University of Pennsylvania, Philadelphia, Pennsylvania 19104, \\ ${ }^{5}$ Laboratory of Cellular and Molecular Biology, National Cancer Institute, Bethesda, Maryland 20892, ${ }^{6}$ Life and Medical Sciences Institute, University of \\ Bonn, 53121 Bonn, Germany, and 7Laboratory of Cell Signaling, University of Tokyo, Tokyo, Japan 113-0033
}

Mutant genes that underlie Mendelian forms of amyotrophic lateral sclerosis (ALS) and biochemical investigations of genetic disease models point to potential driver pathophysiological events involving endoplasmic reticulum (ER) stress and autophagy. Several steps in these cell biological processes are known to be controlled physiologically by small ADP-ribosylation factor (ARF) signaling. Here, we investigated the role of ARF guanine nucleotide exchange factors (GEFs), cytohesins, in models of ALS. Genetic or pharmacological inhibition of cytohesins protects motor neurons in vitro from proteotoxic insults and rescues locomotor defects in a Caenorhabditis elegans model of disease. Cytohesins form a complex with mutant superoxide dismutase 1 (SOD1), a known cause of familial ALS, but this is not associated with a change in GEF activity or ARF activation. ER stress evoked by mutant SOD1 expression is alleviated by antagonism of cytohesin activity. In the setting of mutant SOD1 toxicity, inhibition of cytohesin activity enhances autophagic flux and reduces the burden of misfolded SOD1. These observations suggest that targeting cytohesins may have potential benefits for the treatment of ALS.

Key words: ALS; autophagy; ER stress; proteotoxicity; unfolded protein response

\section{Introduction}

Amyotrophic lateral sclerosis (ALS) is a neurodegenerative disease in which motor neurons die, leading to progressive weakness and respiratory failure (Shook and Pioro, 2009). The incidence of ALS is $\sim 1-2$ per 100,000 and $90 \%$ of cases arise in a sporadic

Received Dec. 2, 2013; revised April 19, 2015; accepted May 4, 2015.

Author contributions:J.Z., L.Z., X.J., J.T., Y.A., P.A.R., and R.G.K. designed research; J.Z., L.Z., J.M.-P., X.J., J.T., and A.S. performed research; K.H. and H.I. contributed unpublished reagents/analytic tools; L.Z., M.F., Y.A., P.A.R., and R.G.K. analyzed data; J.Z., L.Z., and R.G.K. wrote the paper.

This work was supported by the National Institutes of Health (NIH Grants AG042179, NS077909, and NS052325 to R.G.K.; Grant AG-18001 to Y.A., and Grant CA-009140 to J.T.) and the Muscular Dystrophy Association (Development Grant MDA 4264 to J.Z.).X.J. and P.A.R. are supported by the intramural program of the NIH (Project BC007365). M.F. and A.S. are supported by the Deutsche Forschungsgemeinschaft (Grant SFB704). H.I. is supported by KAKENHI from the Japan Society for the Promotion of Science and the Strategic Research Program for Brain Sciences by the Ministry of Education, Culture, Sports, Science and Technology, Japan. Stable cell lines were generous gift from Nava Zisapels (NSC-34 cells inducibly expressing WT or mutant SOD). We thank Angela Jablonski, John Flibotte, Vladimir Marshansky, Marco Boccitto, and Ria Lim for thoughtful discussions of this work; Daniel Klionsky, Beth Levine, and David Rubinzstein for measurements and interpretations of autophagic flux experiments; Samuel Todd Lamitina for help in imaging reporter worms in Figure 3; Meera Sundurum for help interpreting the genotyping data for the Arf-1.1 deletion allele (RB1535); Brigid Jensen and Judith Grinspan for the oligodendrite cultures that were used in Figure 4C; and Robert Baloh and Jacqueline 0'Rourke for consultation on assays for monitoring misfolded proteins. Some C. elegans strains were provided by the Caenorhabditis Genetics Center, which is funded by NIH Office of Research Infrastructure Programs (Grant P40 0D010440). The tm1447 and tm1877 strains were generously provided by the Shohei Mitani Laboratory (Tokyo Women's Medical University School of Medicine, Japan).

*J.Z. and L.Z. are co-first authors.

The authors declare no competing financial interests.

Correspondence should be addressed to Robert G. Kalb, Children's Hospital of Philadelphia, 3615 Civic Center Blvd, CHOP/ARC \#814, Philadelphia, PA 19104. E-mail: kalb@email.chop.edu.

J. Zhai's present address is Shriners Hospitals Pediatric Research Center, Temple University School of Medicine, 3500 North Broad Street, Philadelphia, PA 19140

DOI:10.1523/JNEUROSCI.5032-13.2015

Copyright $\odot 2015$ the authors $\quad 0270-6474 / 15 / 359088-18 \$ 15.00 / 0$ manner. In the remaining individuals, there is a family history of ALS (familial ALS, fALS) and/or an allied neurodegenerative disorder (Cleveland and Rothstein, 2001; Al-Chalabi and Hardiman, 2013). The identification of the disease-causing and disease-related gene defects have enabled the creation of models of disease by expression of the mutant gene in cells or animals (Shaw, 2005; Rothstein, 2009). Studies using these models of disease have provided a glimpse into the biological processes that go awry and underlie ALS pathophysiology, such as protein misfolding and accumulation, endoplasmic reticulum (ER) stress, dysfunctional intracellular trafficking, excitotoxicity, mitochondrial dysfunction, neuroinflammation, and abnormal RNA processing (Ferraiuolo et al., 2011; Ling et al., 2013).

The first mutant gene identified to cause fALS was superoxide dismutase 1 (SOD1) (Rosen, 1993). Since the original description, $>160$ different mutations in SOD1 have been identified in SOD1-associated fALS cases (Wroe et al., 2008). Although some mutations impair dismutase activity (conversion of superoxide to hydrogen peroxide), most do not. Therefore, whereas a loss of function could contribute to the pathogenic mechanism, it is generally agreed that the mutations confer a toxic gain of function. Accumulation of misfolded conformers of mutant SOD might be "the" toxic gain of function that drives subsequent pathological events.

The ADP-ribosylation factor (ARF) GTPases are a phylogenetically conserved family of proteins involved with membrane trafficking, lipid metabolism/signaling, actin remodeling, and lipid droplet formation (D'Souza-Schorey and Chavrier, 2006). 
Several of these ARF-governed processes are perturbed in ALSparticularly mutant SOD1-induced defects in ER-Golgi trafficking leading to ER stress (Urushitani et al., 2008; Saxena et al., 2009; Wang et al., 2011). Based on these overlaps, we examined the contributions of cytohesin-ARF signaling in cell- and animalbased models of ALS. We provide evidence that inhibition of cytohesin activity protects against mutant protein toxicity, likely by reducing ER stress and stimulating autophagic protein clearance.

\section{Materials and Methods}

Source of reagents. SecinH3 was synthesized as described previously (Hafner et al., 2006). The trophic factors ciliary neuronotrophic factor (CNTF), brain-derived neurotrophic factor (BDNF), neurotrophin 4 (NT-4), cardiotrophin 1 (CT-1), and glial-derived neurotrophic factor (GDNF) used for spinal cord neuron cultures were from Alomone Labs. All other reagents were obtained from Sigma-Aldrich and were of the highest grade available. The source of primary antibodies was as follows: cytohesin 1, cytohesin 3, and hSOD1 (Abcam); GFP and HA (Santa Cruz Biotechnology); ATF4, CHOP, PDI, LC3, and p62 (Cell Signaling Technology); Myc, actin (Sigma-Aldrich); cytohesin 2 (ProteinTech); and panArf (Thermo Scientific). MS785 was generated as described previously (Fujisawa et al., 2012). Chicken anti-rodent MAP2 (ab5392-25; Abcam) was used in immunocytochemical studies. Rabbit anti-human $\mathrm{Cu} / \mathrm{Zn}$ SOD (ADI-SOD 100; Enzo Life Sciences).

Tissue culture. Rat mixed spinal cord neuron cultures were prepared as described previously (Mojsilovic-Petrovic et al., 2006). Briefly, Sprague Dawley rat dissociated embryonic day 15 (E15) spinal cord neurons were added to a confluent monolayer of astrocytes prepared from the cortex of postnatal day 2 rat pups. One to two days later, AraC (5 $\mu \mathrm{M})$ (C6645; Sigma-Aldrich) was added for $24 \mathrm{~h}$ to arrest astrocyte proliferation. Cultures were maintained in culture medium consisting of astrocyteconditioned medium supplemented with $10 \mathrm{ng} / \mathrm{ml} \mathrm{CNTF,} \mathrm{BDNF,} \mathrm{NT-4,}$ CT-1, and GDNF; $50 \%$ of the medium was replaced with fresh medium every $3 \mathrm{~d}$. For pure astrocyte cultures, the addition of dissociated neurons was omitted. Oligodendrocyte cultures were created as described previously (Feigenson et al., 2011). Cell lines (e.g., Neuro N2a, HeLa, NSC34, HEK 293) were cultured in DMEM with $10 \%$ fetal bovine serum and antibiotics (100 $\mu \mathrm{g} / \mathrm{ml}$ penicillin and $100 \mu \mathrm{g} / \mathrm{ml}$ streptomycin). For stable cell lines, selection pressure was maintained by the addition of G418 $(700 \mu \mathrm{g} / \mathrm{ml})$ plus hygromycin B $(200 \mu \mathrm{g} / \mathrm{ml})$ until used. Stable NSC-34 cells were incubated with doxycycline $(1 \mu \mathrm{g} / \mathrm{ml})$ to induce wtSOD1-GFP or G93A mutant SOD1-GFP protein expression. For pharmacology experiment, cultures were treated with either secinH3 (10 or $50 \mu \mathrm{M})$ or vehicle (DMSO). For autophagy studies, bafilomycin A1 (Baf A1; SigmaAldrich, final concentration $400 \mathrm{~nm}$ ) and 3-methyl adenine (SigmaAldrich, final concentration $10 \mathrm{~mm}$ ) were used.

DNA constructs and recombinant herpes simplex virus. Coding sequences for cytohesins 1-3 were amplified from a mouse spinal cord cDNA library (Stratagene) and cloned into pcDNA3.1/Myc-His (Invitrogen) and pEGFP (Clontech). Dominant-negative (DN) mutants of cytohesins (E156K Cy2 and E161K Cy3) were engineered by mutagenesis using the QuikChange Site-Directed Mutagenesis Kit (Agilent). ARF mutants have been described previously (Zhang et al., 1994; Radhakrishna and Donaldson, 1997). Human wild-type (WT) or G85R or G37R mutant SOD1 constructs were generated as described previously (Zhai et al., 2005). Unless specifically specified, in all experiments in which neurons were infected with herpes simplex virus (HSV) to express mutant SOD, the G85R mutant version was used. WT and p150 glued were gifts from Erika Holzbaur (University of Pennsylvania, Philadelphia, PA). For transduction of primary cultured spinal cord neurons, cDNAs were cloned into HSV p1006 (+) and packaged by the Viral Gene Transfer Core at the Massachusetts Institute of Technology. The veracity of all constructs was confirmed by DNA sequencing.

The design of miRNA targeted to cytohesins followed the rules described in the "BLOCK-iT Pol II miR RNAi" kit by Invitrogen (version F, 2010). $5^{\prime}$ and $3^{\prime}$ flanking sequences were added to facilitate subcloning into the p1006 (+) HSV amplicon vector (for description, see http://mcgovern.mit.edu/technology/viral-core-facility).

RNA extraction, reverse transcription, and RT-PCR. Total RNA was extracted from mouse brain and spinal cord tissues of either sex using TRIzol reagent (Invitrogen). All RNA samples were reverse transcribed into cDNA using the Superscript II Reverse Transcriptase kit (Invitrogen). For RT-PCR, the following primers were used: cytohesin 1: $5^{\prime}$ gaagggctcaacaagacagc- $3^{\prime}$ and $5^{\prime}$-atgattgcgaaggacaggac- 3 '; cytohesin 2 : $5^{\prime}$-cagccattggggactaccta- $3^{\prime}$ and $5^{\prime}$-ctcggtctgggttgaagaag- $3^{\prime}$; cytohesin 3 : $5^{\prime}$-attcaacatggaccccaaaa- $3^{\prime}$ and $5^{\prime}$-agggttgcacaggcagtatc- $3^{\prime}$; cytohesin 4 : $5^{\prime}$-gctacgtgctgtccttctcc- $3^{\prime}$ and $5^{\prime}$-gcttcttggggtcctctacc- $3^{\prime}$; ARF1: $5^{\prime}$-caga acacccaaggcttgat- $3^{\prime}$ and $5^{\prime}$-ctgtggcgtagagagtgcag-3'; ARF2: $5^{\prime}$-cacagtctg ggatgttggtg- $3^{\prime}$ and $5^{\prime}$-ggtttttgagctggttggag- 3 ; ARF3: $5^{\prime}$-gtggttgacagcaatga tcg- $3^{\prime}$ and $5^{\prime}$-agccagtccaagcttcata- $3^{\prime}$; ARF4: $5^{\prime}$-tatgggatgttggtggtcaa- $3^{\prime}$ and $5^{\prime}$-tgtagcacaagtggcttgga- $3^{\prime}$; ARF 5: $5^{\prime}$-cagatgcggatccttatggt- $3^{\prime}$ and $5^{\prime}$-atgag gccetgagtgttctg- $3^{\prime}$; ARF6: $5^{\prime}$-caagttcaacgtgtgggatg- $3^{\prime}$ and $5^{\prime}$-agggctgcacatacc agttc- $3^{\prime}$.

Immunocytochemistry. Tissue culture cells were fixed in freshly prepared $4 \%$ paraformaldehyde in $0.1 \mathrm{~m}$ phosphate buffer, $\mathrm{pH} 7.4$, for 30 min at room temperature. The fixed cells were permeabilized with $0.1 \%$ Triton X-100 for $10 \mathrm{~min}$ before incubation with primary antibodies overnight at $4^{\circ} \mathrm{C}$. After extensive washes with PBS, cells were incubated with Alexa Fluor-conjugated secondary antibody for $2-6 \mathrm{~h}$ at room temperature. The mounted cells were examined by laser-scanning confocal microscopy (Olympus Fluoview). Controls without primary antibody verified the authencity of the immunocytochemical staining.

Quantification of motor neurons. The number of SMI32-positive neurons with cell body diameter $25 \mu \mathrm{m}$ or greater were counted in three randomly selected fields per coverslip, and the mean value was obtained (for methodological details, see Mojsilovic-Petrovic et al., 2006, 2009). In each experiment, at least three independent coverslips were used per condition and the results presented were obtained for at least four independent cultures and experiments.

Coimmunoprecipitation, lysate fractionation, and Western blotting. Cells were lysed with ice-cold cell lysis buffer containing the following (in mM): 50 HEPES, pH 7.9, $150 \mathrm{NaCl}, 1$ EGTA, $1.5 \mathrm{MgCl}_{2}, 50 \mathrm{NaF}, 1$ PMSF, and $1 \mathrm{Na}_{3} \mathrm{VO}_{4}$, along with $10 \%$ glycerol, $1 \%$ Triton $\mathrm{X}-100$, and mammalian protease inhibitor mixture (Sigma-Aldrich). Cells were then clarified by centrifugation at $14,000 \mathrm{rpm}$ for $15 \mathrm{~min}$ at $4^{\circ} \mathrm{C}$. Brains of adult mice were snap frozen, minced, resuspended in cell lysis buffer, and clarified by centrifugation at $14,000 \mathrm{rpm}$ for $30 \mathrm{~min}$ at $4^{\circ} \mathrm{C}$. Cell lysates and brain extracts were normalized for protein content (Pierce) and incubated with antibodies of interest. Immunocomplexes were then precipitated with protein A/G agarose, washed four times with lysis buffer, eluted by boiling in SDS-PAGE sample buffer, and subjected to Western blot analysis. Western blots were visualized and quantified using the LI-COR Odyssey Infrared Imaging System without saturating the protein bands. The intensity value was normalized against the actin loading control. Data analyzed were from three independent experiments.

To detect misfolded SOD using MS785 in neuron cultures, cells were solubilized in lysis buffer containing the following (in $\mathrm{mM}$ ): 50 Tris- $\mathrm{HCl}$, pH 8.0, $150 \mathrm{NaCl}, 10 \mathrm{EDTA}$, and 1 PMSF, along with 1\% deoxycholate and $1 \%$ Triton $\mathrm{X}-100$, at $4^{\circ} \mathrm{C}$ for $15 \mathrm{~min}$, centrifuged at $14,000 \mathrm{rpm}$ on a tabletop Microfuge for $10 \mathrm{~min}$, and the supernatant was removed for incubation with $1 \mu \mathrm{g}$ of MS785 for $14 \mathrm{~h}$ at $4^{\circ} \mathrm{C}$. Anti-rat Ig-conjugated magnetic beads were then added (Life Technology), incubated for $1 \mathrm{~h}$, and then isolated with a magnet. The beads were washed twice in highsalt buffer (20 mм Tris-HCl, pH 7.5, $500 \mathrm{~mm} \mathrm{NaCl}, 1 \%$ Triton X-100, 5 mM EDTA) and 4 times with low-salt buffer (20 mm Tris-HCl, pH 7.5, $150 \mathrm{~mm} \mathrm{NaCl}, 5 \mathrm{~mm}$ EDTA) before resuspension in $2 \times$ sample buffer, subjected to SDS-PAGE, transferred to nitrocellulose membranes, and immunoblotted with anti-human SOD antibody.

To study soluble and insoluble fractions of SOD, cells were washed twice with cold PBS and harvested in lysis buffer: $50 \mathrm{~mm}$ Tris, $\mathrm{pH}$ 8.0, 10 $\mathrm{mm} \mathrm{MgCl}_{2}, 15 \mathrm{~mm} \mathrm{NaCl}, 1 \%$ Triton X-100, 5\% glycerol, and 1\% protease inhibitor mixture (Sigma-Aldrich P2714-1BTL). The cell lysate was sonicated and centrifuged at $100,000 \times g$ for $30 \mathrm{~min}\left(\right.$ at $4^{\circ} \mathrm{C}$ ). The supernatant was collected and designated the "soluble fraction." The pellet was resuspended in urea buffer containing $7 \mathrm{~m}$ urea, $2 \mathrm{~m}$ thiourea, $4 \%$ 
CHAPS, and $30 \mathrm{~mm}$ Tris- $\mathrm{HCl}, \mathrm{pH}$ 8.5. After sonication, the lysate was centrifuged at 20,000 $\times g$ for $30 \mathrm{~min}$ and the supernatant was designated "insoluble fraction." The protein concentration was determined using the Bradford assay (Bio-Rad).

Caenorhabditis elegans. We used six strains of worms for these studies: (1) WT (N2 Bristol), (2) worms engineered to express G85R mutant SOD fused to YPF thoughout the entire nervous system (Psnb-1::G85R SOD1$Y F P)$, (3) mutant SOD worms with enhanced nervous system RNAi (Psnb-1::G85R SOD1-YFP; [pCFJ90 (Pmyo-2-2m,Cherry);Punc-119sid1];sid-19pk3321) (Lim et al., 2012), (4) mutant SOD worms on an ARF6 mutant background (Psnb-1::G85R SOD1-YFP; ARF6(Tm1447), (5) mutant SOD worms on an ARF1.2 mutant background (Psnb-1::G85R SOD1-YFP; ARF1.2(ok796), and (6) worms in which the Arf-1.2 promoter drives expression of GFP; in a dpy-5 mutant background with dpy-5 rescue coinjection marker (BC12796 dpy-5(e907) I;sEx 12796 [rCesB0336.2::GFP + pCeh361]). All animals were maintained on standard nematode growth medium (NGM) plates seeded with Escherichia coli OP50 at $20^{\circ} \mathrm{C}$ (Brenner, 1974).

RNAi knock-down and locomotor assays in C. elegans. Each RNA interference (RNAi) colony was grown overnight in LB medium containing ampicillin $(50 \mu \mathrm{g} / \mathrm{ml})$ and $200 \mu \mathrm{l}$ was seeded on NGM plates containing isopropylthiogalactoside $(1 \mathrm{~mm})$ to induce double-stranded RNA expression. Feeding RNAi clones for Grp1 and efa- 6 were obtained from Thermo Scientific (ORFeome) and Source Bioscourse LifeSciences (MRC) and sequenced before use to verify authenticity. Identical results were obtained from the two sources of feeding RNAi experiments. For locomotor experiments, larval stage 4 (L4) animals were placed on RNAi plates overnight. On the next day, young adult animals were transferred to a fresh RNAi plate and allowed to lay eggs for another $4-6 \mathrm{~h}$. Progeny were subsequently tested for locomotor activity.

C. elegans locomotor behavior was tested in a swimming assay as described previously (Lim et al., 2012). Briefly, a total of 15-25 adult worms were allowed to lay eggs for $4 \mathrm{~h}$. When larvae reached the L4 stage, their locomotor behavior was blindly recorded on a videocamera and tracked using the Parallel Worm Tracker program (http://wormsense.stanford. edu/tracker). Behavior was also recorded at an adult stage ( $24 \mathrm{~h}$ after L4). On average, five replicates containing seven to 10 animals per group were tested and at least three independent experiments were performed for each locomotor assay. Animal tracks were analyzed on MATLAB (The MathWorks) to determine the average speed (in millimeters per second).

SOD1 proteins. The maltose binding protein (MBP) tagged SOD1 WT and G93A, MBP-2 SOD1 WT and MBP-2x SOD1 G93A, were expressed in BL21(DE3) cells. The recombinant proteins were purified with amylose resin (New England BioLabs) according to the manufacturer's instructions.

Cytohesin GEF activity assay. His6-cytohesin 2 was expressed in and purified from bacteria as described previously for his6Brag2 (Jian et al., 2012). MyrARF6 was purified as described previously (Ha et al., 2005), with some modifications (the myrARF6 purified in this manner is GTP bound). To convert the myrARF6.GTP to myrARF6-GDP, the myrARF6 sample (purified from $1 \mathrm{~L}$ of bacterial culture) was kept in a buffer containing the following (in mM): 20 Tris- $\mathrm{HCl}, \mathrm{pH}$ 8.0, $25 \mathrm{NaCl}, 1 \mathrm{MgCl}_{2}, 1$ DTT, 2 EDTA, and $10 \mathrm{~mm}$ GDP, along with $1 \%$ Triton X-100. Next, $1 \mu \mathrm{M}$ GST-BRAG2 (Sec7-PH) was added to the myrARF6-GTP sample to catalyze exchange of GDP for GTP to convert myrARF6-GDP. The sample was incubated at $30^{\circ} \mathrm{C}$ for $100 \mathrm{~min}$. The treated myrARF6 sample was passed through glutathione beads five times to remove GST-BRAG2 (Sec7-PH). The flowthrough was then applied to a HiLoad 16/60 Superdex 75 column preequilibrated in the following (in mM): 20 Tris, $\mathrm{pH} 8.0$, $25 \mathrm{NaCl}, 1 \mathrm{MgCl}_{2}$, and 1 DTT, alogn with $0.1 \%$ Triton X-100 and $50 \mu \mathrm{M}$ GDP. More than $95 \%$ of the myrARF6 contains GDP when prepared by this method (Randazzo et al., 1995; Jian et al., 2010; Jian et al., 2012). The high $\mathrm{MgCl}_{2}$ was used in this reaction to slow down the spontaneous nucleotide exchange. The reactions also contained $0.5 \mathrm{~mm}$ large unilamellar vesicles (LUVs) and $0.5 \mu \mathrm{m}$ myrARF6.GDP, with $10 \mathrm{~nm}$ His6cytohesin 2. LUVs were prepared by extrusion with lipids purchased from Avanti Polar Lipids. They contained 40\% phosphatidylcholine, $25 \%$ phosphatidylethanolamine, $15 \%$ phosphatidylserine, $9 \%$ phosphatidylinositol, $1 \%$ phosphatidylinositol 4,5-biphosphate, and 10\% choles- terol. The reactions were incubated at $30^{\circ} \mathrm{C}$ for $3 \mathrm{~min}$ and terminated with $2 \mathrm{ml}$ of ice-cold buffer containing the following (in mM): 20 Tris, $\mathrm{pH}$ $8.0,100 \mathrm{NaCl}, 10 \mathrm{MgCl}_{2}$, and 1 dithiothreitol. Protein-bound nucleotide was trapped on nitrocellulose and the bound radioactivity was counted by liquid scintillation. Less than $5 \%$ of the myrARF6.GDP exchanged nucleotide in the absence of cytohesin 2 under this condition.

ARF.GTP pull-down assays. HeLa cells were transfected with ARF6HA/pcDNA3.1, together with WT hSOD1, G85R hSOD1, or G93A hSOD1, all in pcDNA3.1/Myc-His vector. Transfected cells were harvested $24 \mathrm{~h}$ after transfection. ARF6.GTP level was determined as described previously (Yoon et al., 2005). Briefly, cells were washed twice with ice-cold PBS and lysed in lysis buffer (50 mM Tris, pH 7.5, $100 \mathrm{~mm}$ $\mathrm{NaCl}, 2 \mathrm{~mm} \mathrm{MgCl}_{2}, 1 \%$ Triton X-100) supplemented with protease and phosphatase inhibitor mixture (Thermo Scientific). Immobilized GSTVHSGATGGA3 was incubated with cleared cell lysates at $4^{\circ} \mathrm{C}$ for $2 \mathrm{~h}$ on a rotator, washed twice with lysis buffer, and eluted with SDS sample buffer. The bound ARF6-HA.GTP was detected by Western blot using antibody against $\mathrm{HA}$.

Measurement of XBP1 splicing. RNA templates for RT-PCR consisted of total RNA isolated using the RNA easy kit (Qiagen) per the manufacturer's protocol. Three micrograms of RNA was retrotranscribed into cDNA using random hexamers (Superscript II Reverse Transcriptase; Invitrogen) per the manufacturer's protocol. RT-PCR was performed using the GeneAMP PCR system 9700 (ABI). The primers used for RTPCR were as follows: forward, rat XBP1, AAACAGTAGCAGCACAG ACTGC and reverse, rat XBP1, TCCTCCTGGGTAGACCTCTGGGAG. These primers were designed to enable detection of both the unspliced form of XBP1 (XBP-1u) and the spliced form of XBP-1 (XBP-1s). Splicing that results in the removal of a $26 \mathrm{nt}$ intron. PCR conditions were as follows: 1 hold $94^{\circ} \mathrm{C}$ for $4 \mathrm{~min}, 94^{\circ} \mathrm{C} 10 \mathrm{~s}, 63^{\circ} \mathrm{C} 30 \mathrm{~s}, 72^{\circ} \mathrm{C} 30$ s repeated for 35 cycles, 1 hold $72^{\circ} \mathrm{C} 1 \mathrm{~min}$, and $4^{\circ} \mathrm{C} \infty$. Agarose gel electrophoreses was used to differentiate between XBP-1u and XBP-1s.

Measurements of the autophagic system. We assessed the level of activation of the autophagic system using the most current methodologies and tools (Mizushima et al., 2010). The extent of autophagosome formation was determined by the ratio of LC3-II relative to actin (by Western blot) and quantification of p62 abundance. To assay autophagic flux, HeLa cells were grown to $\sim 85 \%$ confluence in the presence or absence of $50 \mu \mathrm{M}$ secinH $3 \times 24 \mathrm{~h}$. Then, Baf Al or vehicle was added to the culture medium of each experiment for $4 \mathrm{~h}$, followed by cell lysis and immunoblotting for LC3, p62, and actin. Densitometric determination of band intensities is reported and reflects the mean of four or more biological replicates. These experiments were repeated no less than three times from independently generated cultures.

Statistics. Pairwise comparisons used two-tailed Student's $t$ test. When three or more experimental groups were compared, ANOVA and post hoc analysis with significance set at $p<0.05$.

\section{Results}

\section{Inhibition of ARF GEFs benefits models of ALS}

As a first step toward determining the importance of cytohesins and ARF GTPases in models of neurodegenerative disease, we used a recently developed small-molecule inhibitor of cytohesin GEF activity. There are four known mammalian cytohesins, termed cytohesin 1-4, and secinH3 has been shown to inhibit all except cytohesin 4 (Hafner et al., 2006). We investigated whether administration of secinH3 to spinal cord neuron cultures expressing mutant proteins exacerbated or protected against toxicity.

Dissociated spinal cord neurons were grown on an astrocyte monolayer for $14 \mathrm{~d}$ in vitro (DIV) before infecting with recombinant HSV engineered to express $\beta$ galactosidase ( $\mathrm{LacZ}$ ), WT human SOD1 (WT-SOD1), or the G85R mutant version of human SOD1 (mut-SOD1). At the dose and titer of virus we used, $>95 \%$ of neurons express the transgene under this culture conditions (Mojsilovic-Petrovic et al., 2006, 2009). At the time of infection and every other day thereafter, cultures were treated with either $50 \mu \mathrm{M}$ secinH3 or vehicle. After 7 DIV, the cultures were fixed, 


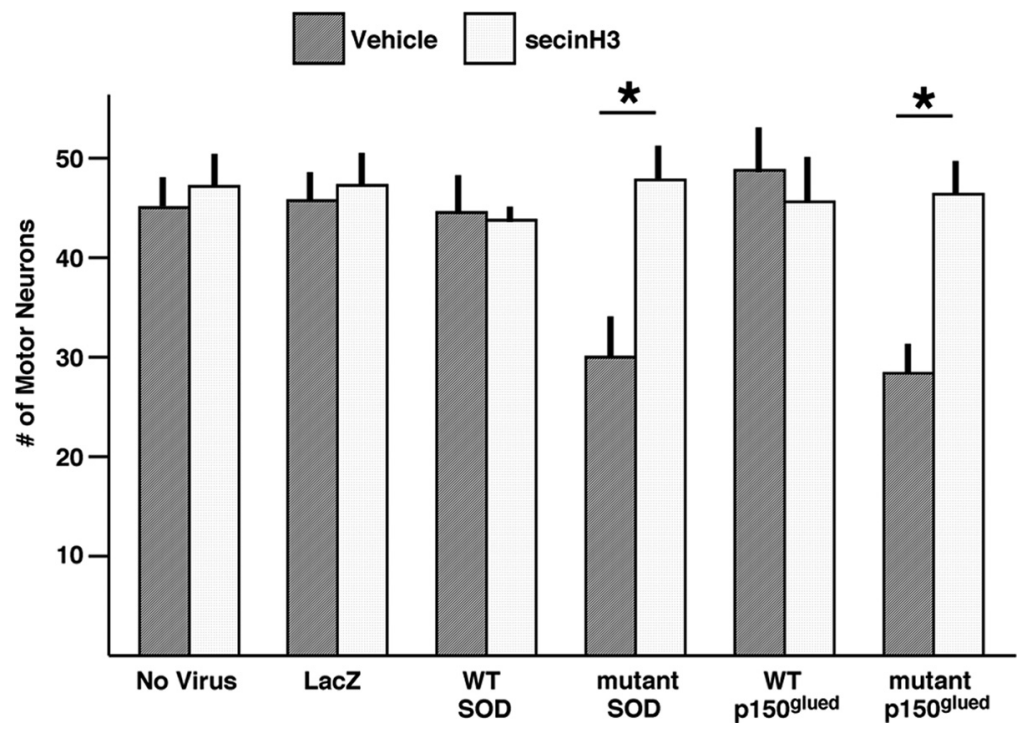

Figure 1. SecinH3 protects motor neurons from disease-linked mutant protein-induced toxicity. Rat DIV 14 dissociated spinal cord neurons were infected with recombinant HSV engineered to express LaCZ, WT SOD1, mutant SOD1, WT p150 ${ }^{\text {Glued }}$, or mutant p150 Glued . Parallel plates were treated every other day with $50 \mu \mathrm{m}$ secinH3 or vehicle for $7 \mathrm{~d}$. Cultures were fixed, immunostained using SMI-32, and the motor neuron (identified by previously validated criteria; Mojsilovic-Petrovic et al., 2006) number was quantified. No statistically significant difference in the number of motor neurons was detected in uninfected cultures versus cultures expressing LacZ or WT SOD1 or p150 Glued. Treatment with secinH3 showed no effect on survival in these cultures. Approximately $50 \%$ of motor neurons died after $7 \mathrm{~d}$ of infection with HSV-mutant SOD1 or HSV-mut p150 ${ }^{\text {Glued }}$; treatment with secinH3 completely rescued motor neuron death induced by mutant SOD1 or mutant $p 150^{\text {Glued }}$ ( $p$ ost hoc, $p<0.05$ ).

stained with a previously validated immunocytochemical marker of motor neurons, and surviving motor neurons were quantified (Mojsilovic-Petrovic et al., 2006). Group differences in motor neuron survival were found by ANOVA $\left(F_{(7,16)}=14.10, p<\right.$ $0.0001)$. Compared with cultures that were not infected with viruses, no motor neuron death was seen in HSV-LacZ or HSV-WT SOD1-infected cultures (Fig. 1). There was no statistically significant difference in motor neuron survival in these cultures when treated with secinH3 compared with vehicle. Consistent with prior work (Mojsilovic-Petrovic et al., 2006, 2009; Perlson et al., 2009; Jeong et al., 2011), we found that $~ 50 \%$ of motor neurons died after $7 \mathrm{~d}$ of infection with HSV-mutant SOD1 and treatment with secinH3 completely blocked this death ( post hoc, $p<0.05$ ) (Fig. 1). Identical results were obtained using HSV engineered to express the G37R mutant version of SOD (data not shown). To determine whether the effect of secinH3 was restricted to the toxic actions of mutant SOD1, we expressed a different WT and mutated protein that has been implicated in a genetic form of motor neuron disease, p150 ${ }^{\text {glued }}$ (Puls et al., 2003). Group differences in motor neuron survival were found by $\operatorname{ANOVA}\left(F_{(5,18)}=\right.$ $33.69, p<0.0001$ ). As described previously (Mojsilovic-Petrovic et al., 2009), expression of mutant, but not WT p150 ${ }^{\text {glued }}$, led to the loss of $\sim 50 \%$ of motor neurons under these culture conditions, and treatment of secin $\mathrm{H} 3$ completely rescued this phenotype (post hoc, $p<0.05$ ) (Fig. 1). These observations suggest that antagonism of cytohesin GEF activity by secinH3 protects against multiple insults that can cause death of motor neurons.

To consolidate the finding that antagonism of cytohesin-ARF GTPase signaling by secinH3 protects against multiple insults that can cause death of motor neurons, we investigated whether expression of DN forms of cytohesins would also protect against mutant SOD1 toxicity. We engineered recombinant HSV to express WT or DN forms of cytohesins 2 and 3 (cytohesin 2 E156K and cytohesin $3 \mathrm{E} 161 \mathrm{~K}$ ). Both WT and DN forms of cytohesins express at similar levels by Western blot (data not shown). To determine whether expression of either WT or DN versions of cytohesin 1, 2, or 3 alone were toxic, we counted surviving motor neurons in cultures expressing these viruses and compared these values with LacZ or no virus controls. We found that the number of surviving motor neurons in cultures expressing WT or DN versions of cytohesins 2 or 3 was similar to those expressing $\beta$-galactosidase or no virus infection, indicating that expression of WT or DN cytohesins 2 and 3 alone does not cause motor neuron death in cultures (Fig. 2A).

We then infected spinal cord cultures with various combinations of WT or mutant SOD1 and WT or DN cytohesin 2 at 14 DIV and counted motor neuron survival $7 \mathrm{~d}$ later. In previous work, we found that infecting our spinal cord cultures with two viruses led to a very high level of both transgenes in the same neurons and that this approach was not toxic per se (Mojsilovic-Petrovic et al., 2009). Group differences in motor neuron survival were found by $\operatorname{ANOVA}\left(F_{(5,32)}=32.06, p<\right.$ $0.0001)$. Compared with uninfected or HSV-LacZ infected cultures, neither expression of the WT nor the DN cytohesins adversely affected motor neuron survival (Fig. 2B). There was no statistically significant difference in motor neuron numbers between cultures expressing WT SOD1 versus WT SOD1 + WT cytohesin 2 or WT SOD1 + DN cytohesin 2. Expression of mutant SOD1 led to an $\sim 50 \%$ death of motor neurons that was rescued by coexpression of DN cytohesin 2 but not WT cytohesin 2 ( post hoc, $p<0.05$; Fig. $2 B$ ). We performed a similar analysis of cultures with various combinations of WT or mutant SOD1 and WT or DN cytohesin 3 at 14 DIV and counted motor neuron survival 7 d later. Group differences in motor neuron survival were found by ANOVA $\left(F_{(5,35)}=11.44, p<0.0001\right)$. There was no statistically significant difference in motor neuron number between cultures expressing WT SOD1 versus WT SOD1 + WT cytohesin 3 or WT SOD1 + DN cytohesin 3 (Fig. 2C). Expression of mutant SOD1 led to an $\sim 50 \%$ death of motor neurons that was rescued by coexpression of DN cytohesin 3 but not WT cytohesin 3 (post hoc, $p<$ 0.05; Fig. 2C).

In an additional test of the participation of cytohesins in mutant protein toxicity, we used RNAi. Alignment of the rat cytohe$\sin 1,2$, and 3 sequences identified a region that was common to all three (Fig. 2D). We created a miRNA to this sequence as well as a scrambled sequence control ("scr miRNA") and determined that the miRNA to the sequence common to cytohesins 1,2 , and 3 ("pan-Cy miRNA") effectively knocked down these targets in a heterologous expression system (data not shown). We then engineered HSV to express the pan-Cy miRNA or the scr miRNA, infected spinal cord cultures, and determined that the active miRNA effectively knocked down its targets in neurons (Fig. 2E). Armed with these tools, we then studied cultures that were either uninfected or infected with HSV-LacZ (at DIV 14) along with two different doses of HSV-pan-Cy miRNA and assessed survival at 21 DIV. We determined that neither LacZ expression nor LacZ + miRNA expression influenced motor neuron survival 
A

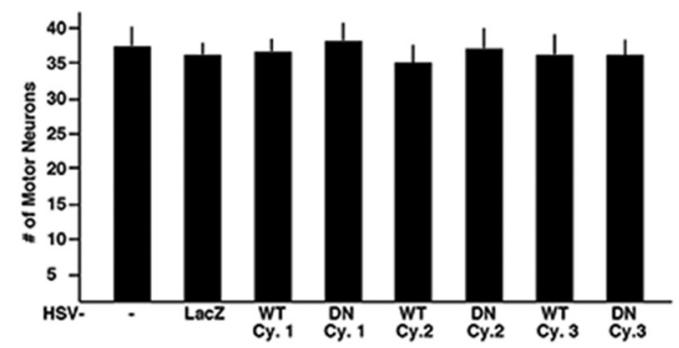

D
B

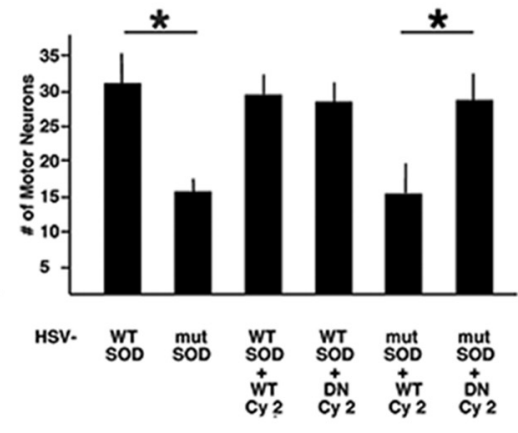

C

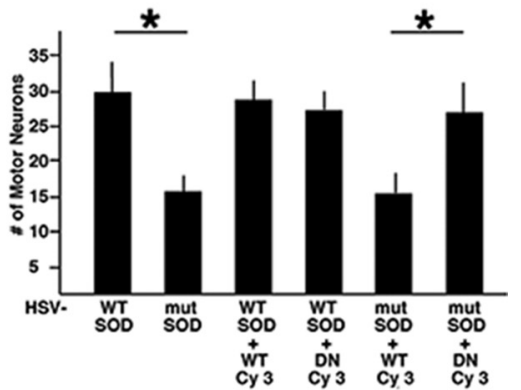

Rat Cytohesin 1 5' CGGAAGCCGAACTGCTTTGAGCTTTATAAC 3' Rat Cytohesin 2 5' AAGAAGCCGAACTGCTTTGAGCTTTATATC 3' Rat Cytohesin 3 5' CGGAAGCCGAACTGCTTTGAGCTTTACATT 3'

\section{Pan cytohesin}

target sequence
....GCCGAACTGCTTTGAGCTTTA...

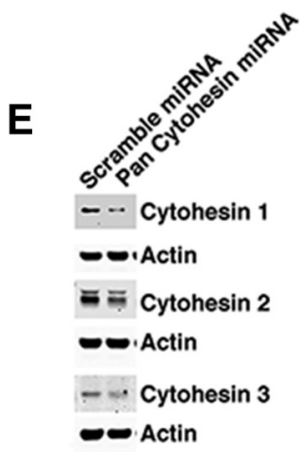

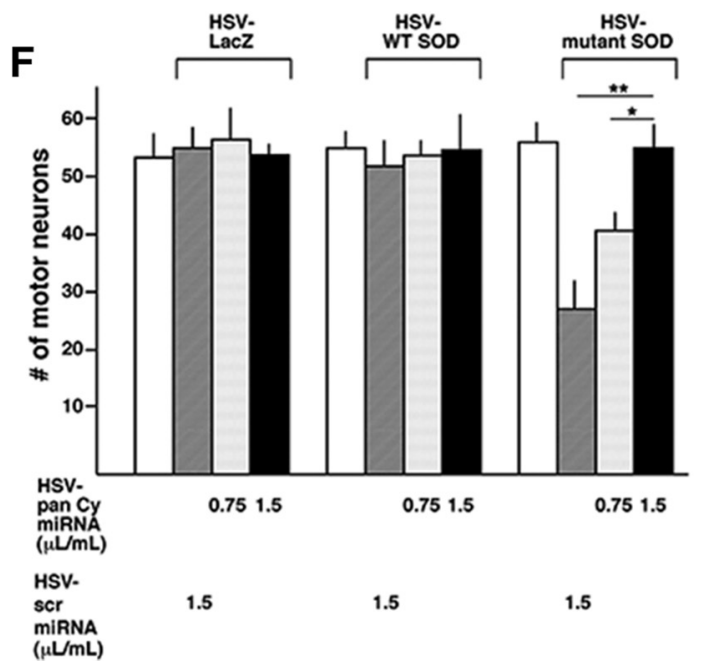

Figure 2. Expression of DN mutant cytohesins or knock-down of cytohesins 1, 2, and 3 protects motor neurons from mutant SOD1 toxicity. DIV 14 spinal cord neuron cultures were infected with various combinations of HSV expressing LacZ; WT cytohesins; DN mutant cytohesins; active or inactive miRNA to cytohesins 1,2, and 3; and WT or mutant SOD1 and the number of surviving motor neurons was determined $7 \mathrm{~d}$ later. $A$, Quantitative analysis showed that expression of LacZ, WT, or DN mutant cytohesins 1-3 alone did not cause death of motor neurons under these culture conditions. $\boldsymbol{B}$, Expression of mutant SOD1 alone led to an $\sim 50 \%$ death motor neurons compared with WT SOD1 alone and this effect was rescued by coexpression of DN cytohesin 2 , but not WT cytohesin 2 (post hoc, $p<0.05$ ). C, Similar analysis showed that coexpression of DN cytohesin 3, but not WT cytohesin 3, rescued motor neurons from mutant SOD1-induced toxicity ( $p o s t$ hoc, $p<$ 0.05). D, Alignment of the sequence of rat cytohesins 1,2, and 3 identifies a region of identity in the coding region and this sequence was selected for targeting for RNAi. The selected region is called the pan-Cy target sequence and the miRNA to this sequence is called the pan-Cy miRNA. $\boldsymbol{E}$, Lysates from spinal cord cultures infected with HSV engineered to express the pan cytohesin miRNA or a scrambled sequence control were immunoblotted for Cy1, Cy2, or Cy3 and actin. The active miRNA targeting all three cytohesins led to a reduction in neuronal levels of Cy1, Cy2, and Cy3. $F$, No difference in motor neuron number was seen in uninfected cultures versus cultures infected with HSV-LaCZ + HSV engineered to express a scrambled (scr) sequence miRNA death or two doses of the pan cytohesin miRNA. No difference in motor neuron number was seen in uninfected cultures versus cultures infected with HSV-WT SOD + HSV engineered to express an scr sequence miRNA death or two doses of the pan-Cy miRNA. Expression of mutant SOD was toxic to motor neurons and knock-down of Cy1, Cy2, and Cy3 with the pan-Cy miRNA protected against this insult in a dose-dependent manner $\left({ }^{*} p<0.05 ;{ }^{* *} p<0.01\right)$.

(compared with uninfected cultures). Similarly, expression of WT SOD was not toxic in this culture system with or without coexpression of the pan-Cy miRNA (Fig. 2F). In contrast, expression of mutant SOD with or without pan-Cy miRNA led to group differences by ANOVA $\left(F_{(3,46)}=5.499, p=0.01\right)$. Mutant SOD led to an $\sim 50 \%$ reduction in motor neuron survival (post hoc, $p<0.05$ ) and coexpression of the pan-Cy miRNA led to a dosedependent rescue of toxicity ( post hoc, $p<0.05$ ). The higher dose of pan-Cy miRNA completely prevented the toxicity of mutant SOD expressed expressed in our cultures (Fig. $2 F$ ).

Considering the three complementary approaches taken to reduce cytohesin activity (i.e., pharmacological, expression of DN constructs, and simultaneous knock-down of cytohesins 1, 2, and 3), our observations suggest that loss of cytohesin activity blocks the toxic actions of mutant SOD1 in mammalian neurons.

To extend these observations to an in vivo model, we used $C$. elegans engineered to express yellow fluorescent protein-tagged G85R mutant SOD1 in the nervous system. These animals display an uncoordinated ("unc") locomotor phenotype, although no motor neuron death has been observed (Wang et al., 2009; Lim et al., 2012). Because there are at least two cytohesin homologs in $C$. elegans genome (Grp1 and efa-6), we investigated whether feeding RNAi rescued the unc phenotype of the mutant SOD1expressing worms. We found no improvement in the locomotor impairment in mutant SOD1 expressing C. elegans grown on RNAi expressing bacteria targeting Grpl or efa- 6 versus empty vector (data not shown). This was true at L4 as well as in young adults.

RNAi is either not robust in the nervous system of C. elegans or has unpredictable efficacy. A recent advance in the field is to eliminate the SID1 gene throughout the organism and transgenically express SID1 only in neurons (Calixto et al., 2010). SID1 is important for the uptake of RNA and knock-out in peripheral tissues and its overexpression in neurons enhances neuronal RNAi efficacy. We considered the possibility that RNAi to Grp1 and efa- 6 was ineffective in ameliorating mutant SOD1 toxicity because of the relative resistance of neurons to feeding RNAi. To test this idea, we created worms that express mutant SOD1 in a 
A
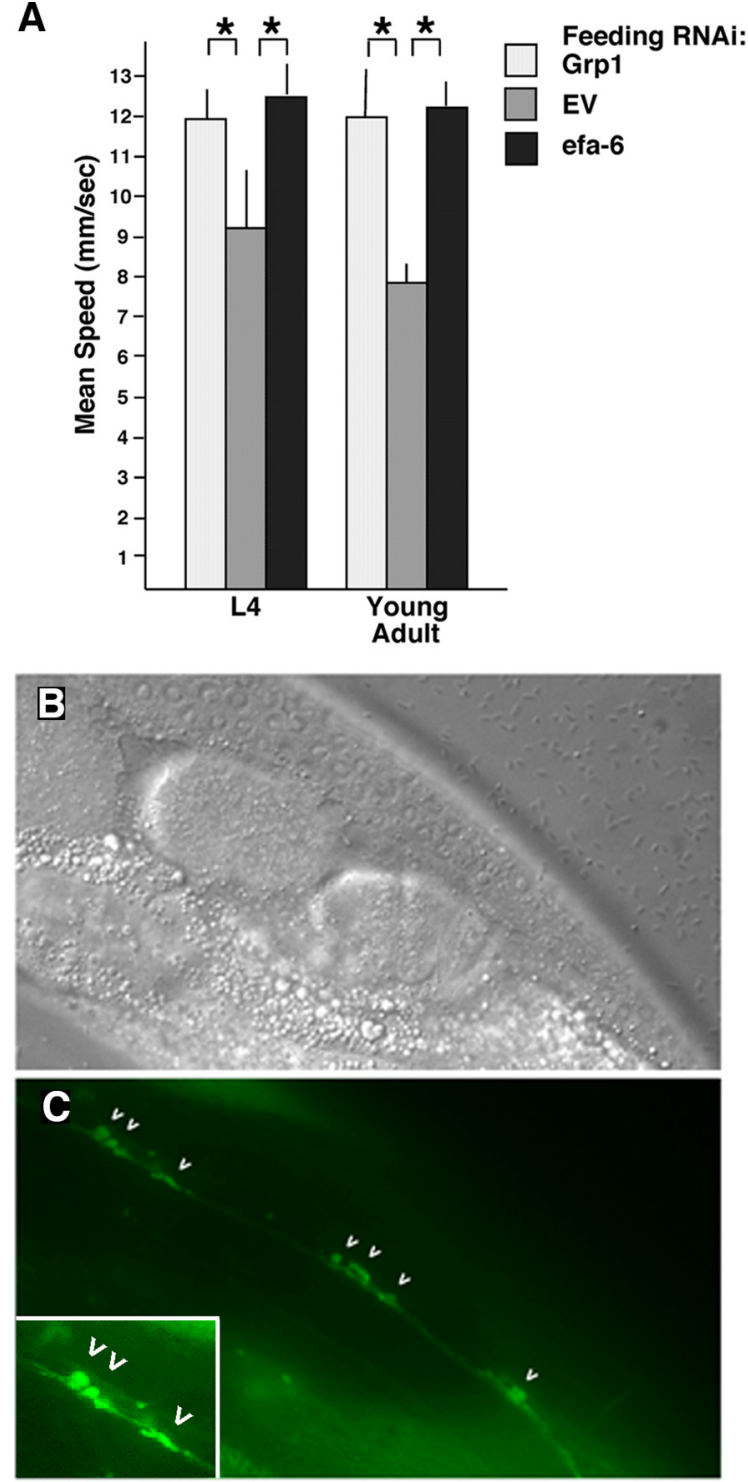

D

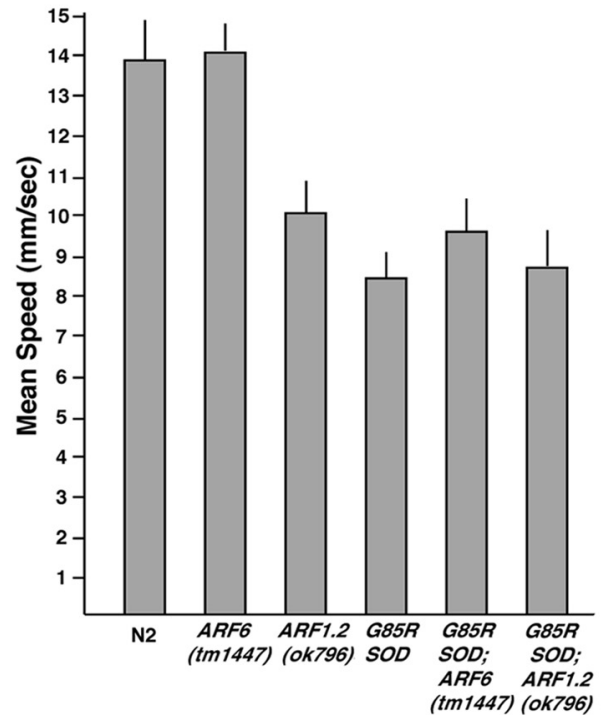

Figure 3. Silencing expression of either cytohesin homolog Grp1 or efa-6 in C. elegans improves locomotor function in SID1/G85R-transgenic worms. Synchronized worms were fed on
SID1-null background with transgenic expression of SID1 in neurons (denoted mutant SOD1;SID1; Lim et al., 2012) and repeated the feeding RNAi experiments. Compared with worms fed empty vector, RNAi knock-down of Grp1 or efa- 6 to the mutant SOD1;SID1 worms led to rescue of the locomotor defect (Fig. $3 A$ ). The improvement in locomotion by reduction of worm cytohesins was seen at both the L4 and young adult stages. Because there is no neuronal death (only neuronal dysfunction) in the mutant SOD1 worm (Wang et al., 2009), the beneficial effects of Grp1 or efa-6 knock-down must ameliorate a dysfunctional biological response to mutant SOD1 expression.

There are at least four genes in the C. elegans genome that are likely to be ARF orthologs: ARF1.1 (gene name, F45E4.1), ARF1.2 (B0336.2), ARF3 (F57H12.1), and ARF6 (Y116A8C.12). To determine which cells are expressing these ARFs, we began by examining a reporter strain in which the ARF1.2 promoter drives GFP (BC12796). We found many labeled neurons in the ventral nerve cord, commissural neurons, and neurons associated with the vulva and pharynx (Fig. $3 B, C$ ). Several other structures, such as muscle cells and the pharynx, also expressed GFP. No other reporter strains are available, so the expression pattern of other ARFs is unknown.

At the time that we initiated these studies, we found that deletion mutant alleles existed at all four ARF loci in publically accessible repositories. The existing Arf-3 deletion allele (tm1877) removes a substantial portion of the $\mathrm{N}$ terminus of the protein, but also deletes the $\mathrm{C}$ terminus of the adjoining gene, F57H12.10. The existing Arf-1.1 deletion allele (RB1535) is restricted to the Arf-1.1 locus, but our genotyping suggests that, during mutagenesis, both a deletion and duplication of the locus occurred and thus a usable Arf-1.1 loss-of-function mutant worm does not exist. Our analysis indicates that only for $A R F 1.2$ and ARF6 was the deletion restricted to the gene of interest. In light of this, we began our inquiry into the contribution of these ARFs to mutant SOD toxicity. The ARF6 mutant allele tm1447 contains a 2263 bp deletion that includes the first 5 (of 6) coding exons and is very likely to be a null. The ARF-1.2 mutant allele ok796 contains an 1140 bp deletion in the middle of the open reading frame and is probably a null or severe hypomorph. These strains were first outcrossed five times with the N2 strain before being crossed with a G85R mutant SOD1 worm to generate double-mutant worms. In the swimming assay, we observed a modest locomotor defect in ARF1.2 mutant worms compared with the N2 control strain at L4 (Fig. 3D) and the young adult stage (data not shown), whereas no locomotor defects were found in ARF6 mutant worms (Fig. 3D). Double-mutant worms (mutant SOD on a mutant ARF6 background) showed the same locomotor defects as mutant SOD worms. Similarly, mutant SOD on a mutant ARF1.2 background showed identical locomotor defects compared with mutant SOD worms; this was true at the L4 stage as well as in young adults (Fig. 3D and data not shown). Therefore, whereas suppression of cytohesin activity is neuroprotective, loss of individual ARFs does not rescue the lo-

bacteria expressing RNAi and their progenies were analyzed for locomotor function with a swimming test. $A$, RNAi knock-down of Grp1 or efa-6 in SID1/G85R S0D1 worms led to rescue of the locomotor defect at both the $L 4$ and young adult stages $\left({ }^{*} p<0.05 ;{ }^{* *} p<0.01\right)$. B, Phase contrast view of worm strain $\mathrm{BC} 12796$ in which the ARF1.2 promoter drives GFP. C, GFP is seen expressed in several neurons in the ventral nerve cord and in neurites. Cell bodies are noted with arrowheads and the inset shows a higher-power image clearly identifying neurons. $\boldsymbol{D}$, In the swimming assay, neither deletion of Arf1.2 nor Arf6 had a beneficial effect on the mutant SOD1 worm locomotor defect. 
A
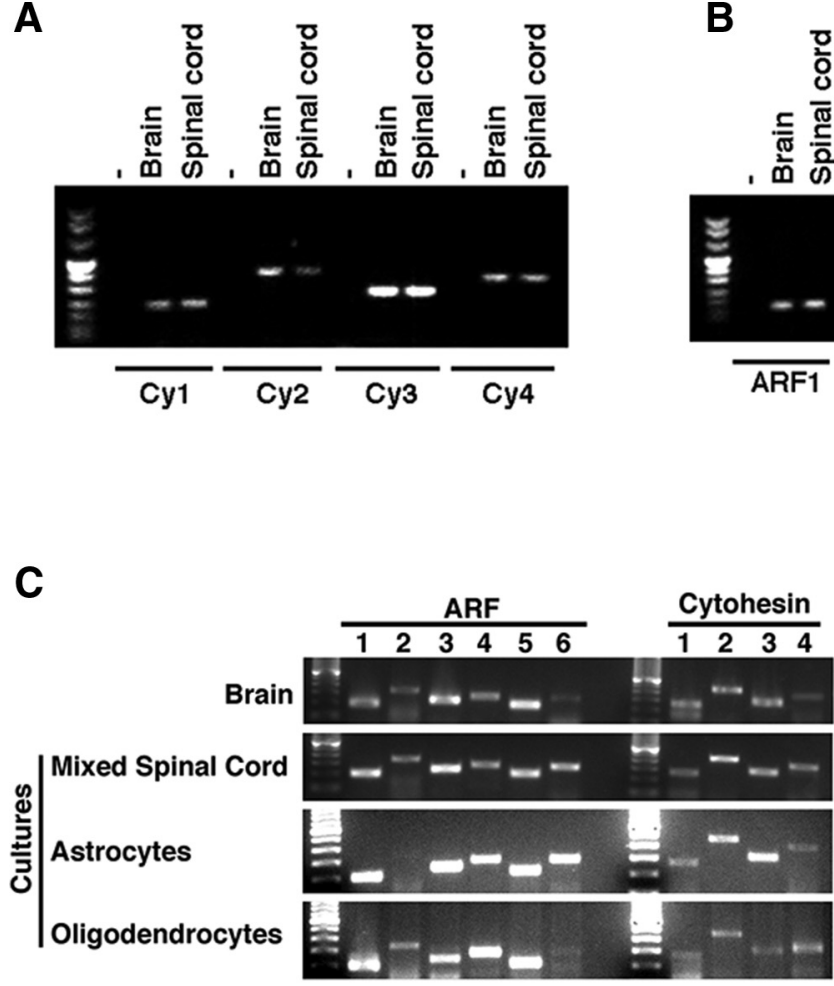

B
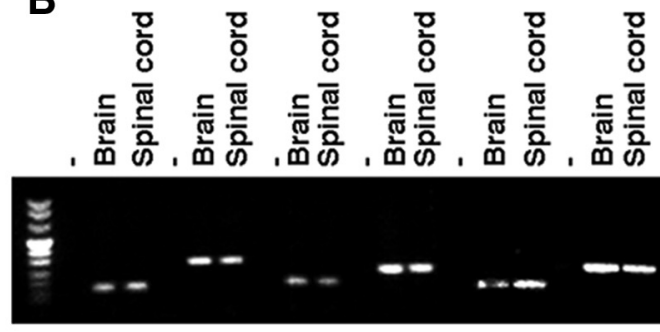

$\overline{\text { ARF1 }} \overline{\text { ARF2 }} \overline{\text { ARF3 }} \overline{\text { ARF4 }} \overline{\text { ARF5 }} \overline{\text { ARF6 }}$
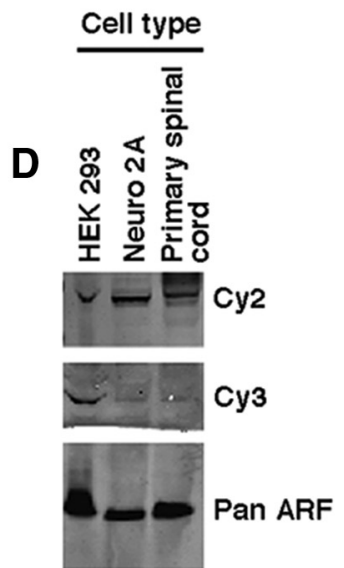

Figure 4. Expression patterns of cytohesins and ARFs in neuronal tissues. $A, R T-P C R$ analysis showed that cytohesins $1-4$ are detected in mouse brain and spinal cord. $B$, RT-PCR analysis showed that ARFs 1-6 are detected in mouse brain and spinal cord. C, RT-PCR analysis showed that cytohesins 1-4 and ARF1- $6 \mathrm{mRNA}$ are detected in mixed spinal cord cultures and cultures of pure astrocytes and pure oligodendrocytes. The only exception was that ARF 2 was not detected in astrocyte cultures. D, Western blot showing expression of cytohesins 2 and 3 and Arf proteins (using a pan-ARF antibody) in the neuronal cell line Neuro 2a and primary cultured spinal cord neurons used in this study.

comotor defect. These results may indicate that redundant functions allow nondeleted ARFs to substitute for the loss of individual ARFs, a phenomena well described in the ARF literature (Volpicelli-Daley et al., 2005; Popoff et al., 2011). Alternatively, ARF genes for which we did not have mutant alleles (e.g., ARF-1.1 or ARF-3) might play a key role in the neuroprotective actions of cytohesin activity blockade. Targeted mutation in these genes (e.g., using genome editing tools such as TALENs or CRISPR/Cas9; Cermak et al., 2011; Lo et al., 2013) will allow us to address this issue in the future.

In sum, using pharmacological and molecular tools in mammalian tissue culture and nervous-system-specific gene knockdown in C. elegans, we find that inhibition or loss of function of cytohesins has a beneficial effect on cells and animals expressing mutant SOD1.

Cytohesins and ARFs are expressed by multiple cell types The literature on expression patterns of cytohesins and ARFs in nervous tissues is limited, so we determined the expression pattern of these genes in neuronal tissues. We first determined whether cytohesins and ARF GTPases were expressed in adult rodent spinal cord and brain as well as in three in vitro preparations: (1) mixed rat spinal cord neurons grown on astrocytes, (2) pure astrocyte cultures, and (3) pure oligodendrocyte cultures. Using RT-PCR, we found evidence for mRNA for all ARF GTPases (ARFs 1-6) and all cytohesins (cytohesins 1-4) in the brain and spinal cord (Fig. 4A,B). Similarly, we detected mRNA for all ARFs and cytohesins in the three culture platforms (Fig. 4C). The sole exception was the lack of ARF 2 mRNA in pure astrocyte cultures.

Using Western blot, we found expression of endogenous cytohesins 2 and 3 in cultured spinal cord neurons as well as lysates of HEK293 and Neuro 2a cells (Fig. 4D). Cytohesin 3 was apparently present in lower abundance in cultured spinal cord neurons and Neuro 2a cells (Fig. 4C). An antibody that recognizes all ARF GTPase isoforms gave robustly positive immunoblot signal using lysates of cultured spinal cord neurons and lysates of HEK293 and Neuro 2a cells (Fig. 4D). These observations demonstrate that the mRNA for all ARF GTPases and cytohesins are expressed in brain, spinal cord, and cultured spinal cord neurons and, within the limitations of available reagents, at least cytohesins 2 and 3 protein products are expressed in the same tissues.

We next used immunocytochemistry to examine the expression of cytohesins and ARF GTPases in our in vitro cellularmodel-cultured spinal cord neurons. Both cytohesin 2 (Fig. 5A) and cytohesin 3 (Fig. 5D) immunoreactivity was clearly present in cells of these cultures and there was a perfect overlap between the expression of these GEFs and the neuronal marker MAP2 (Fig. 5B, $C, E, F)$. An antibody that recognizes all six ARF GTPases (panARF) similarly stained neurons (Fig. 5G-I). Attempts to label with antibodies to other cytohesins or specific ARF GTPases did not reveal a reliable immunocytological signal. These observations suggest that a minimum of two cytohesins and one or more ARF GTPases are expressed by neurons in our cultures.

\section{Mutant SOD1 associates with cytohesins but does not} influence their ARF guanine nucleotide exchange activity We considered the possibility that human SOD1 complexes with cytohesins. We began by determining whether WT or mutant SOD1 coimmunoprecipitates with cytohesins in a heterologous expression system. We cotransfected myc-tagged WT SOD1, G93A mutant SOD1, or G85R mutant SOD1 with GFP-tagged 

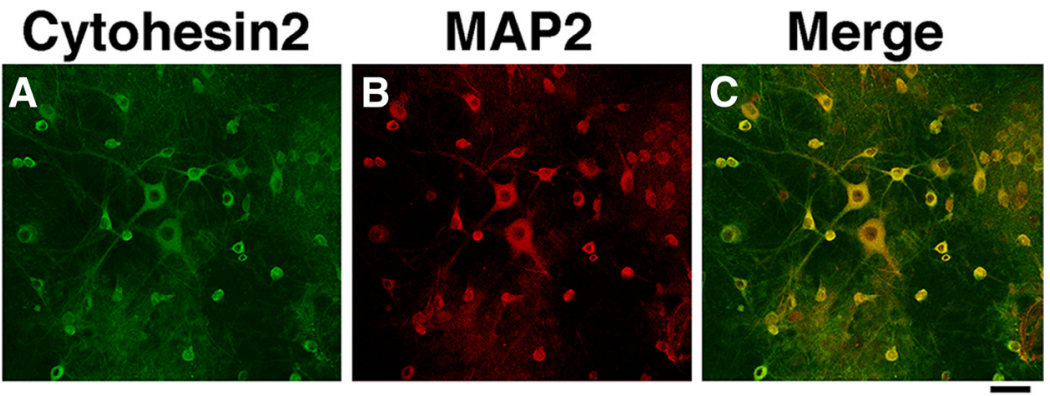

\section{Cytohesin3}
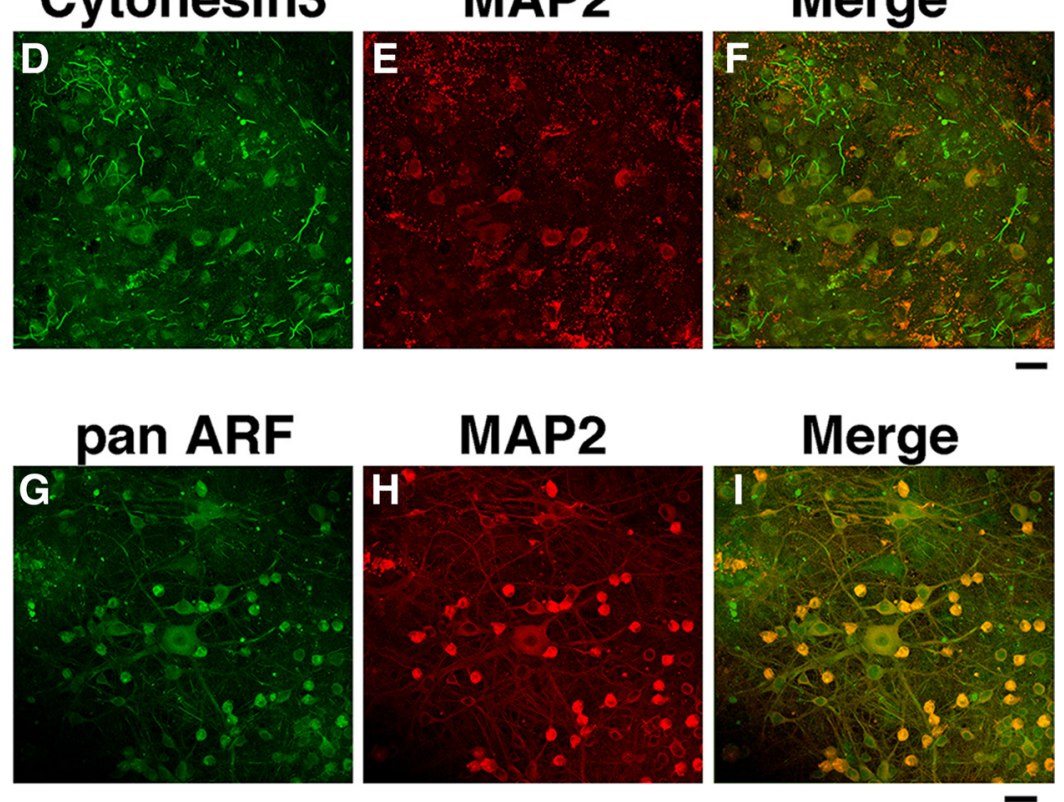

Figure 5. Cytohesins and Arfs are expressed in cultured primary spinal cord neurons. DIV 14 spinal cord neurons were fixed and immunostained for cytohesin $2(\boldsymbol{A})$, cytohesin $3(\boldsymbol{D})$, or pan-ARF $(\boldsymbol{G})$, respectively. The cultures were also stained for the neuronal marker MAP2 to identify neurons $(\boldsymbol{B}, \boldsymbol{E}, \boldsymbol{H})$. Merged images $(\boldsymbol{C}, \boldsymbol{F}, \boldsymbol{I})$ confirmed the expression of cytohesin 2 and 3 and ARF (using a pan-ARF antibody) in primary cultured neurons.

cytohesin 1, 2, or 3. Immunoprecipitation with anti-myc followed by immunoblotting for GFP revealed that all the cytohesins (1, 2, and 3) were brought down (Fig. 6A). Immunoblotting of inputs demonstrates that, in these experiments, expression of cytohesins 1, 2, or 3 does not influence expression of various SOD constructs and, conversely, expression of the SOD constructs does not influence expression of cytohesins 1, 2, or 3. There was a more robust association of each of the cytohesins with the mutant forms of SOD1 than with the WT version (Fig. 6A). In mixed spinal cord cultures expressing G85R mutant SOD, immunoprecipitation with an anti-human SOD antibody (but preimmune mouse Ig) brought down endogenous $\mathrm{Cy} 3$ and human SOD (Fig. 6B). Input levels of human SOD and Cy3 were identical in the starting material. We were unable to detect by coimmunoprecipitation an interaction between endogenous cytohesins and endogenous rodent SOD. Neither the anti-SOD nor the anti-cytohesin antibodies performed well in our immunoprecipitation experiment. The inability to detect an interaction between the endogenous proteins could reflect the normal biology or could result from technical limitations.

Next, we used a well characterized, conformation-specific antibody, MS785 (Fujisawa et al., 2012) that recognizes misfolded human SOD in immunocytological investigations. When mixed spinal cord cultures are infected with HSV G85R mutant SOD, we found punctate misfolded SOD accumulations in the neuronal cell body and distal dendrites (Fig. 6C,D). Immunocytology for $\mathrm{Cy} 2$ revealed diffuse cytoplasmic staining in the cell body and distal dendrites and discrete puncta (Fig. $6 C^{\prime}, D^{\prime}$ ). Some, but not all, misfolded SOD and Cy2 puncta colocalize in distal dendrites (Fig. $\left.6 C^{\prime \prime}, D^{\prime \prime}\right)$. High-magnification images of a neuronal cell body demonstrated that misfolded SOD is distibuted in a "lumpy porridge" pattern. Portions of larger misfolded SOD punta can be seen to overlap with Cy2 staining (Fig. $6 E^{\prime \prime}$, yellow patch noted by arrowhead) adjacent to Cy2 punta that do not colocalize with misfolded SOD (Fig. $6 E^{\prime \prime}$, red patch noted by arrow). Smaller misfolded SOD and Cy2 puncta show partial, Venn-diagram-like overlap (Fig. $6 E, E^{\prime}, E^{\prime \prime}$ noted by circle). A similar immunocytochemical colocalization pattern was seen between misfolded SOD and Cy3 (data not shown).

In sum, these studies show that cytohesins and mutant SOD1 associate in heterologous expression systems as well as in lysates from spinal cord neuron cultures expressing G85R SOD1. Future studies will be needed to determine whether mutant SOD has a preferential associated with active versus inactive cytohesins and the cell biological effects of cytohesin accumulation into punctate structures associated with and unassociated with misfolded SOD.

\section{Effects of SOD on cytohesin GEF} activity and bulk ARF.GTP levels Considering these binding data, we wondered whether the neurotoxicity of mutant SOD1 was mediated through aberrant activation of the guanine nucleotide exchange activity of cytohesins. Isolated ARF releases GDP very slowly, which is the limiting step for GTP binding. Cytohesins catalyze GDP release, allowing subsequent GTP binding. The effect of cytohesins can be measured in an in vitro reaction using purified proteins. In Figure $7 A$, cytohesin 2 was titrated into a reaction containing $0.5 \mu \mathrm{M}$ ARF6.GDP and $10 \mu \mathrm{M}$ GTP $\gamma \mathrm{S}$ with $\left[{ }^{35} \mathrm{~S}\right] \mathrm{GTP} \gamma \mathrm{S}$ as a tracer. After $3 \mathrm{~min}$, the reaction was stopped by diluting 80 -fold into $4^{\circ} \mathrm{C}$ buffer, proteins were trapped on nitrocellulose and protein-bound $\left[{ }^{35} \mathrm{~S}\right]$ was measured by scintillation spectroscopy. Under the conditions of the assay, $<5 \%$ of ARF6 exchanged GTP $\gamma \mathrm{S}$ for GDP in the absence of an exchange factor. GTP $\gamma \mathrm{S}$ binding to ARF6 was increased by the addition of cytohesin 2 with a half maximal effect at $\sim 14$ nM cytohesin 2 (Fig. $7 A$ ). To determine whether SOD1 affected the catalytic activity, purified WT or G93A SOD1 fused to maltose-binding protein was titrated into a reaction containing $5 \mathrm{nM}$ cytohesin 2 and $0.5 \mu \mathrm{M}$ ARF6.GDP (Fig. 7B). A $5 \mathrm{~nm}$ concentration of cytohesin 2 is sufficient to induce $\sim 20 \%$ of the ARF6 to exchange nucleotide under these conditions, a level that would allow detection of either inhibition or activation. SOD1 had no effect on cytohesin 2-catalyzed nucleotide exchange activity. The amount of ARF6.GTP formed was reduced to a small extent by both WT and 
G93A SOD1 at concentrations up to $1 \mu \mathrm{M}$ (Fig. $7 B$ ). This result indicates that SOD1 does not activate cytohesins directly.

The effect of SOD1 on cellular ARF.GTP levels was also determined. Although little or no effect of SOD1 on cytohesin exchange activity was detected in the in vitro assay, SOD1 may increase cytohesin guanine nucleotide exchange activity, and thus myrARF6.GTP levels, by other mechanisms in vivo. For example, SOD1 could be part of an active ternary complex containing cytohesins. Furthermore, the lack of effect in the in vitro assay could be due to improper folding of SOD 1 expressed in bacteria. To measure the effect of SOD1 on cellular ARF-GTP levels, HeLa cells were cotransfected with a plasmid for expression of ARF6 with an HAepitope at the C terminus (ARF6-HA) and a plasmid for either WT or G85R or G93A mutant SOD1. Cells were lysed $24 \mathrm{~h}$ after transfection. ARF6-HA.GTP was separated from ARF6-HA.GDP and other proteins by incubating the lysates with the ARF-binding domain of GGA3 fused to GST, which binds specifically to ARF6-GTP. The ARF6-HA.GTP-GGA3 complex was precipitated with glutathione agarose and the amount of ARF6-HA in the precipitate was quantified by immunoblotting for the HA epitope (Fig. $7 C$, top). We found that total ARF6-HA was increased by the coexpression of SOD1 (Fig. 7C, middle). The levels of ARF6-HA-GTP were also increased (Fig. $7 C$, top). In the experiment shown, the relative ARF6.GTP/total ARF6 ratio was greater for WT and G93A SOD1 than the control or G85R SOD1; however, the increase in ARF6-HA.GTP was much less than the change observed on expressing an exchange factor (quantified in bar graph, Fig. 7D). In short, if SOD1 affects the ARF6-GTP levels in cells, we could not detect the changes by examining the entire cellular pool of ARF6.GTP.

In sum, cytohesins bind SOD (particularly dimeric mutant versions) but do not influence in vitro GEF activity or global ARF6·GTP levels.

\section{ER stress evoked by mutant SOD1} expression is alleviated by secin $\mathrm{H} 3$ Although a cytosolic protein, a portion of cellular mutant SOD1 appears to enter the secretory pathway and this is associated with biochemical markers of ER stress (Urushitani et al., 2008; Wang et al., 2011). Because ARF GTPases play a major role in vesicle trafficking, we wondered whether blocking cytohesin activity influenced SOD1-induced ER stress. Because
A
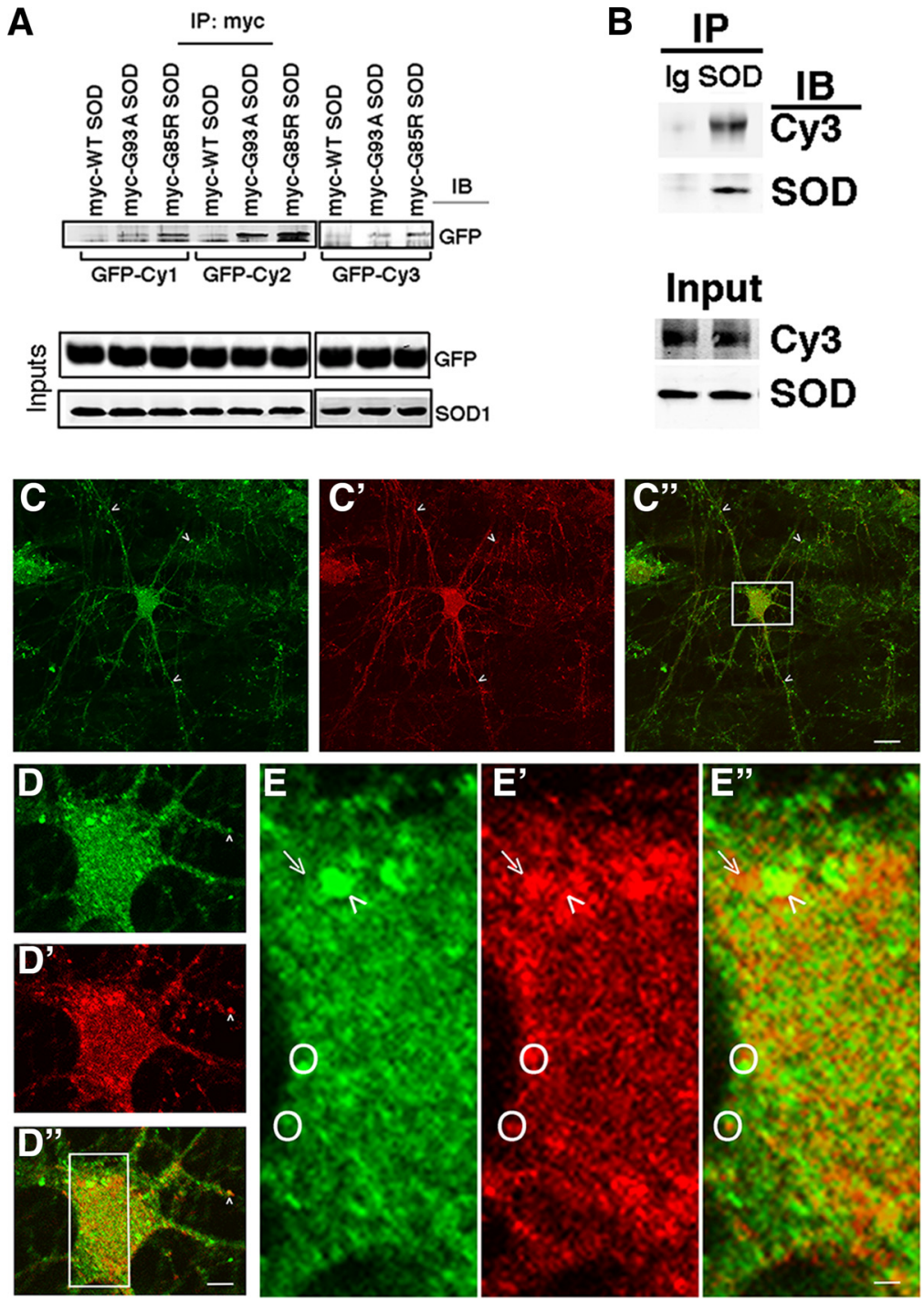

Figure 6. Mutant SOD1 associates with cytohesins. A, Overexpressing GFP-tagged cytohesins and Myc-tagged WT or mutant SOD1 in Neuro 2a cells showed that cytohesins 1-3 were coprecipitated with WT, G93A, or G85R S0D [IP myc, immunoblot (IB) GFP]. There is more robust association between cytohesins and mutant versus WT SOD1. Input levels show that expression of cytohesins did not influence the expression of WT of mutant SOD and expression of WT or mutant SOD did not influence the expression of cytohesins. B, DIV 14 spinal cord cultures were infected with HSV-G85R SOD and, 3 d later, lysates prepared and subjected to immunoprecipitation (IP) with either anti-SOD antibody or preimmune serum (denoted "I $\mathrm{g}^{\prime \prime}$ ) and imunoblotted (IB) for Cy3 or SOD. Material immunoprecipitated human SOD (but not Ig) contains Cy3 immunoreactivity. Loading levels of Cy3 and SOD are equivalent between samples. Spinal cord cultures infected with HSV-G85R SOD were immunostained for misfolded SOD using MS785 and Cy2. C, Misfolded SOD immunoreactivity is seen in the cell body and extensively fills the dendritic tree. Distal dendrite puncta of immunoreactivity are seen (some highlighted with arrowheads). $\boldsymbol{C}^{\prime}$, Cy2 immunoreactivity is seen in the cell body and extensively fills the dendritic tree. Distal dendrite puncta of immunoreactivity are seen (some highlighted with arrowheads). $\boldsymbol{C}^{\prime \prime}$, Merged image of $\boldsymbol{C}$ and $\boldsymbol{C}^{\prime}$ shows that some misfolded SOD and Cy2 puncta colocalize (highlighted with arrowhead). Scale bar, $35 \mu \mathrm{m}$. D, Higher-magnification views of the boxed area in $\boldsymbol{C}^{\prime \prime}$ showing nonhomogeneously distributed misfolded SOD immunoreactivity in the soma and proximal dendrites (an individual puncta highlighted with arrowhead). $\boldsymbol{D}^{\prime}$, Same region imaged for Cy 2 shows nonhomogenous distribution of Cy 2 immunoreactivity in the soma and proximal dendrites. A Cy2 puncta in the proximal dendrite is highlighted with arrowhead. $\boldsymbol{D}^{\prime \prime}$, Merged image of $\boldsymbol{D}$ and $\boldsymbol{D}^{\prime}$ showing that some misfolded SOD and Cy2 puncta colocalize (highlighted with arrowhead). Scale bar, $7 \mu \mathrm{m}$. $\boldsymbol{E}$, Highermagnification view of the boxed area in $D^{\prime \prime}$ showing that misfolded SOD immunoreactivity in the soma adopts a "lumpy porridge" pattern with immunoreactivity concentrates of various sizes. A larger misfolded SOD concentrate is indicated with an arrowhead and an adjacent region without misfolded SOD concentration is indicated with an arrow. Smaller puncta are scattered throughout the cytoplasm, two of which are highlighted with circles. $\boldsymbol{E}^{\prime}$, Cy2 immunoreactivity in the same field is similarly nonhomogeneous with concentrated immuoreactivity of various sizes. Larger and smaller Cy2 concentrations are noted by arrowhead, arrow, and circle. $\boldsymbol{E}^{\prime \prime}$, Merged image of $\boldsymbol{E}$ and $\boldsymbol{E}^{\prime}$ showing that there are regions of colocalization of misfolded SOD and Cy 2 immunoreactivity (yellow in region denoted by arrowhead and circle). In addition, some concentrates of Cy2 immunoreactivity are adjacent to, but do not strictly colocalize with, misfolded SOD (red region denoted by arrow). Scale bar, $1.75 \mu \mathrm{m}$. 
A

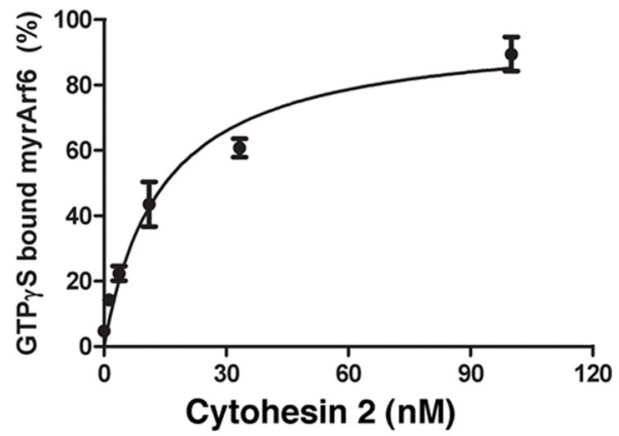

B

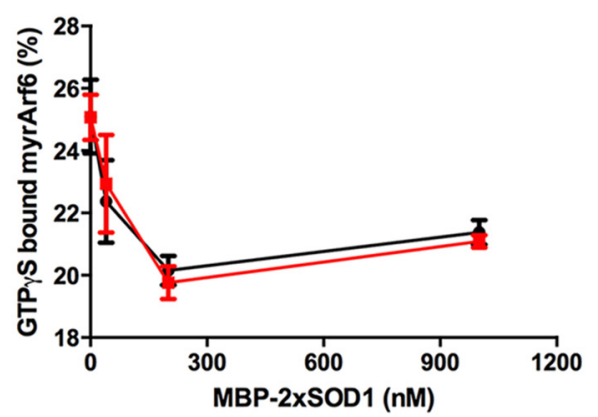

C

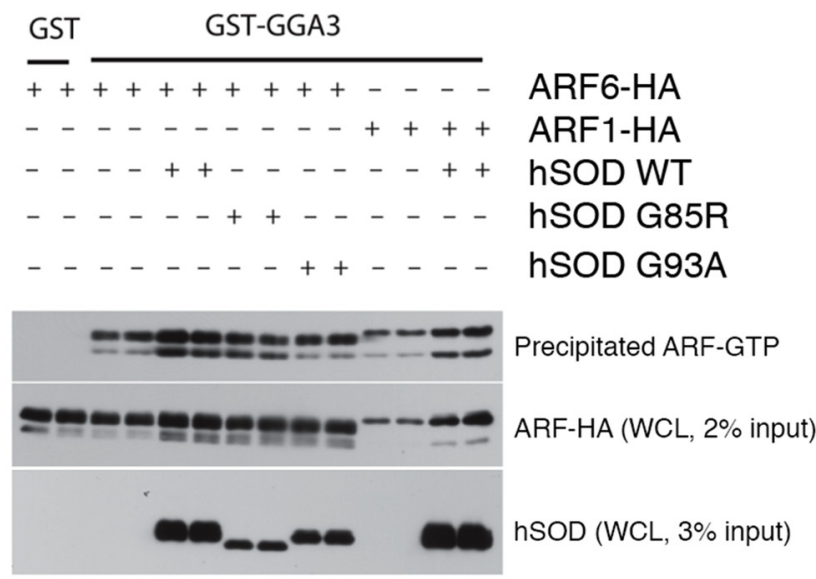

\section{D}

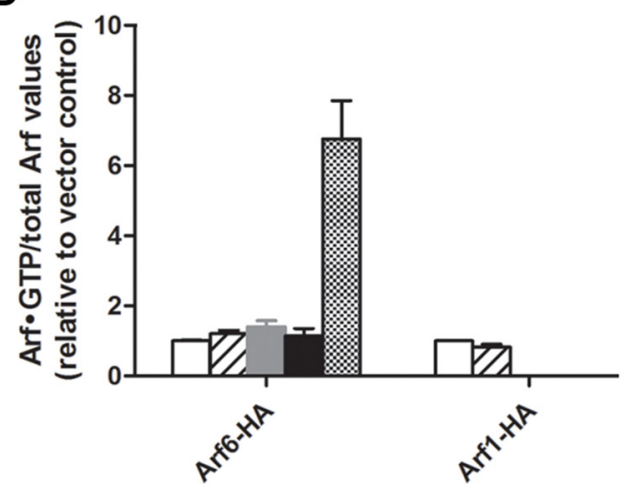

Figure 7. Mutant SOD1 does not increase activation of ARF in vitro or in cells. $A$, In vitro binding analysis showing that GTP $\gamma S$ bound ARF6 was increased by the addition of cytohesin 2 with a half maximal effect at $\sim 14$ nм cytohesin 2. B, In vitro binding analysis showed that SOD1 had little effect on cytohesin 2-catalyzed nucleotide exchange activity. The amount of ARF6.GTP formed was reduced to a small extent ( $<20 \%)$ by both WT and G93A SOD1 at concentrations up to $1 \mu \mathrm{M}$. C, ARF.GTP pull-down assay showing that the relative ARF6.GTP/total ARF6 ratio was greater for WT and G93A SOD1 than the control or G85R S0D1; however, no difference in ARF6.GTP/total ARF6 ratio was found comparing WT and mutant SOD1. D, Bar graph quantification of the Western blot data in $C$. we have not previously characterized this phenomena in our culture system, we began by investigating whether induction of ER stress by application of tunicamycin-induced activation of the inositol-requiring enzyme $1 \alpha$ (IRE1 $\alpha$ ) arm of the unfolded protein response (UPR). When stimulated by dimerization, the endoribonuclease activity of IRE $1 \alpha$ is activated and catalyzes the unconventional splicing of XBP1 (Walter and Ron, 2011). Using a PCR-based method, we found that tunicamycin evokes XBP1 splicing and that this event is completely suppressed by pretreating spinal cord cultures with $\geq 50 \mu \mathrm{M}$ secinH3 (Fig. 8A). We also found that treatment of neurons with HSV engineered to express the pan-Cy miRNA reduced tunicamycininduced XBP1 splicing in a dosedependent manner. The highest dose of recombinant virus suppressed tunicamycininduced XBP1 splicing nearly to the same degree as $50 \mu \mathrm{M}$ secinH3 (Fig. 8B). Next, we investigated whether expression of mutant SOD in our mixed spinal cord neuron cultures (using the neurotropic HSV vector) induced XBP1 splicing. Using a variety of dosing schedules and viral loads, we found no evidence for mutant SOD-evoked XBP1 splicing (although our positive control with tunicamycin confirms that these cells are competent to splice XBP1; Fig. 8C). This observation surprised us because prior in vivo work supports the notion that expression of mutant SOD can stimulate IRE1 $\alpha$ activation (Hetz et al., 2009; Nishitoh et al., 2008; Wang et al., 2011). We considered the possibility that an XBP1 message from astrocytes in our cultures (which are not infected by HSV) was obscuring the splicing signal, so we interrogated pure neuron cultures. We generated pure spinal cord neuron cultures and expressed LacZ or mutant SOD using a variety of dosing schedules and viral loads and found no evidence for mutant SOD evoked XBP1 splicing (although, again, our positive control with tunicamycin confirms that these cells are competent to splice XBP1; Fig. 8D). We conclude that spinal cord neurons are capable of activating the IRE $1 \alpha$ arm of the UPR and this is blocked by application of secinH3 or knock-down of Cy1, Cy2, and Cy3. In addition, we find no evidence that, under these culture and transgene expression conditions, mutant SOD evokes IRE $1 \alpha$ activation.

The second UPR arm is initiated by double-stranded RNA-activated protein kinase (PKR)-like endoplasmic reticulum kinase (PERK) and this leads to activation 

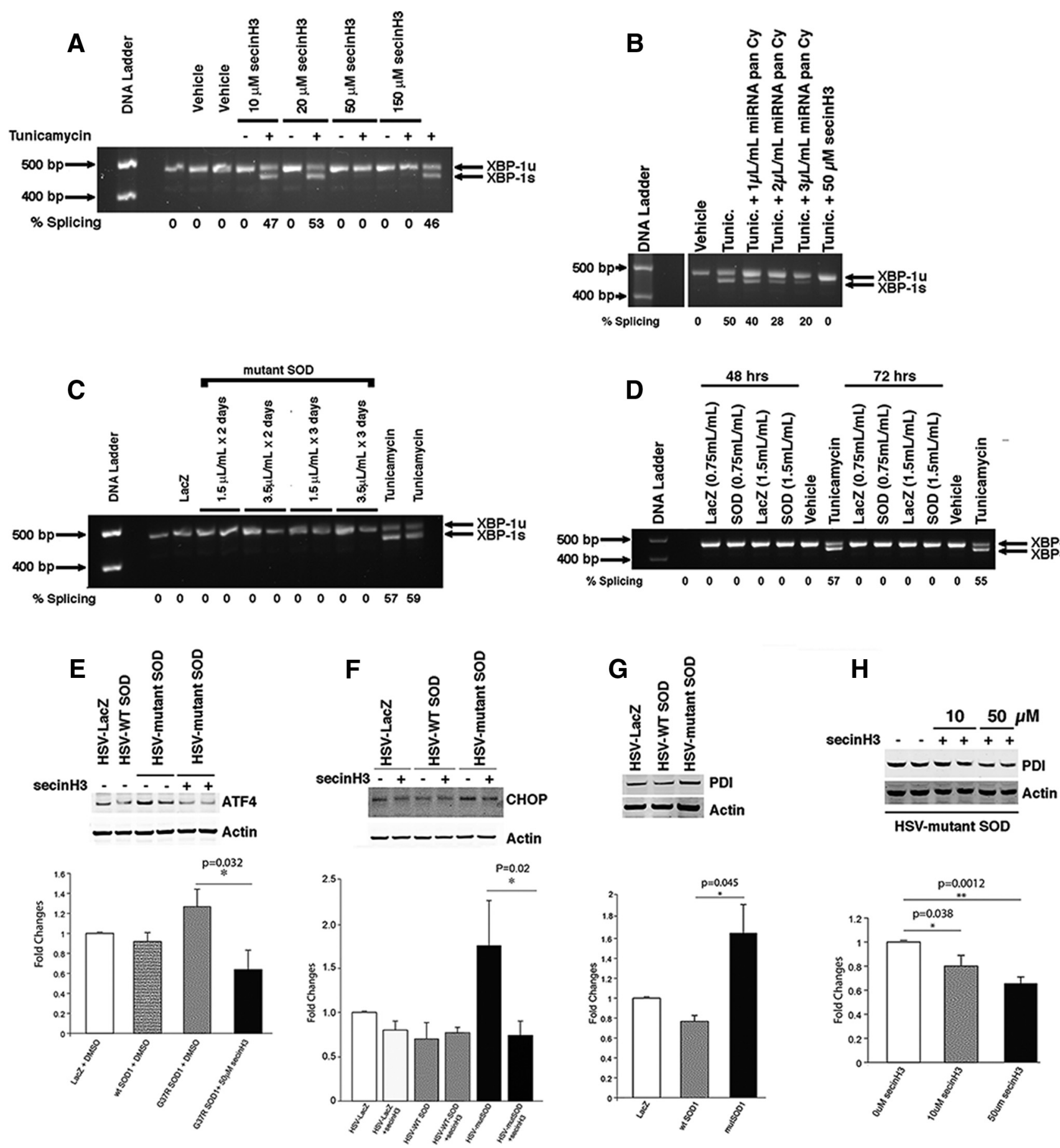

Figure 8. Chemically evoked ER stress in neurons is suppressed by secinH3 and knock-down of Cy1, Cy2, and Cy3; mutant SOD evokes activation of two arms of the UPR and this is suppressed by secinH3. Cultures of primary spinal cord neurons \pm astrocytes were exposed to tunicamycin at DIV 14 or infected with HSV mutant SOD and then lysates were obtained and used for the XBP1-splicing assay. A, Tunicamycin induces XBP1 splicing in mixed spinal cord cultures and this is inhibited by secinH3 treatment ( $\geq 50 \mu \mathrm{M})$. $\boldsymbol{B}$, Tunicamycin induces XBP1 splicing in pure neuronal spinal cord cultures and this is suppressed in a dose-dependent manner by cytohesin knock-down using HSV pan-Cy miRNA. The effect of the $3 \mu$ l dose of virus was similar to secinH3 treatment. C, Varying dosages and schedules of HSV-mutant SOD application to mixed spinal cord cultures did not evoke XBP1 splicing. D, Varying dosages and schedules of HSV mutant SOD application to pure neuronal spinal cord cultures did not evoke XBP1 splicing. Mixed spinal cord cultures were infected with HSV engineered to express LacZ, WT SOD, or mutant SOD and then treated with secinH3 or vehicle for $2 \mathrm{~d}$ before preparation of lysates for further interrogation. $\boldsymbol{E}$, There is an increase of ATF4 expression in mutant SOD1-expressing spinal cord neuron cultures compared with LacZ or WT SOD1. SecinH3 treatment (50 $\mu \mathrm{m})$ blocked this increase. Densitometric quantification of band intensities from $3+$ independent experiments is displayed in the bar graphs below. $\boldsymbol{F}$, Similarly, CHOP expression is increased in mutant SOD1-expressing neurons compared with other experimental groups and treatment with SecinH3 $(50 \mu \mathrm{m})$ blocked this increase. Densitometric quantification of band intensities from $3+$ independent experiments is displayed in bar graphs below. $\mathbf{G}, \boldsymbol{H}$, There is an increase in PDI level in mutant SOD1-expressing neurons comparing with LacZ or WT SOD-expressing neurons and incubation of secinH3 blocked the increase of PDI in mutant SOD1-expressing neurons in an apparently dose-dependent manner. Densitometric quantification of band intensities from $3+$ independent experiments is displayed in the bar graphs below. 
of the ATF4 transcription factor. Compared with spinal cord cultures expressing LacZ or WT SOD1, there was a clear increase in ATF4 expression level as well as CHOP (an ATF4 target gene) in mutant SOD1-expressing neurons (Fig. 8E, F, densitometrically quantified below). Treatment of mutant SOD1-expressing neurons with $50 \mu \mathrm{m}$ secinH3 blocked the increase in ATF4 and CHOP. This effect appeared to be specific; secinH3 treatment did not influence the abundance of $\mathrm{CHOP}$ in neurons expressing LacZ or WT SOD1 (Fig. 8E, F, densitometrically quantified below).

The third UPR arm that we investigated is initiated by ATF6, a transcription factor that is rendered active by ER-stress-induced translocation from the ER to the Golgi apparatus and by proteolysis. Compared with spinal cord cultures expressing LacZ or WT SOD1, there was a clear increase in the abundance of the ATF6 target gene protein disulfide isomerase (PDI or PDIA1) in mutant SOD1-expressing neurons (Fig. 8G, $H$, densitometrically quantified below). Treatment of mutant SOD1-expressing neurons with $50 \mu \mathrm{m}$ secinH3 blocked the increase in PDI in an apparently dose-dependent manner (densitometrically quantified below).

In sum, these experiments indicate that the expression of mutant SOD1 stimulates the two arms of the UPR and that inhibition of cytohesins by secinH3 blunts this response. These observations suggest that, in the setting of proteotoxic stress, inhibition of cytohesins reduces ER stress.

\section{SecinH3 stimulates autophagy}

Because unrestrained ER stress can cause cell death, we posit that the beneficial effects of secinH 3 was mediated, at least in part, by the alleviation of ER stress. One way that this might occur is by enhanced degradation of misfolded proteins either through the ubiquitin-proteasome system or the lysosome-based degradation pathway, autophagy. Macro-autophagy (hereafter referred to as autophagy) is an attractive target for ARF GTPase regulation because of the major role that this class of proteins plays in membrane trafficking and lipid signaling. Recent work has implicated ARF GTPases in various aspects of autophagy (Moreau et al., 2012; Rong et al., 2012). In the next set of experiments, we monitored aspects of autophagy upon expression of mutant SOD1 and assessed the effects of secinH3.

Microtuble-associated protein 1 light chain 3 (LC3) is a mammalian protein specifically associated with autophagosome membrane. Upon induction of autophagy, the cytosolic form of LC3 (LC3-I) is lipidated and recruited to both the inner and outer surfaces of autophagosomes, resulting in the autophagosome-associated LC3-II form. Sequestome 1/SQSTM1 or p62 is incorporated into autophagosomes and is efficiently degraded by autophagy. Cellular levels of p62 inversely correlate with autophagic flux and it is often used as another marker for autophagy induction (Bjørkøy et al., 2005). We began by monitoring the effect of secinH 3 on autophagy induction by assessing the levels of LC3 and p62 proteins. HeLa cells under normal growth conditions were treated with vehicle or increasing amount of secinH3 for $24 \mathrm{~h}$ and the cells were lysed and immunoblotted for LC3 and p62. We found that treatment of HeLa cells with increasing amount of secinH 3 caused a clear increase of LC3-II levels and, conversely, a decrease in p62 levels (Fig. 9A, densitometrically quantified below). In addition, upon $1 \mathrm{~h}$ of starvation of HeLa cells, we detected an increase of LC3-II and a decrease in $\mathrm{p} 62$ and these effects were enhanced by treatment with secinH3. This was not a cell-line-specific phenomena because an increased level of LC3-II was also seen in motor-neuronlike NSC34 cells when treated with secinH3 (Fig. 9B). Impairing lysosome acidification with cloroquine leads to LC3-II accumulation (Mizushima et al., 2010) and serves as a positive control in these experiments.

We next monitored LC3-I and LC3-II levels and the effects of secinH3 upon expression of mutant SOD1 in spinal cord neuron cultures. Spinal cord neuron cultures at DIV 14 were first infected with HSV engineered to express LacZ, WT SOD1, or G85R mutant SOD1. Then, the cultured neurons were treated with $50 \mu \mathrm{M}$ secinH3 for $48 \mathrm{~h}$ before being lysed and blotted for LC3-II levels. We found that expression of mutant SOD1 triggered an increase in the level of LC3-II and treatment of secinH3 enhanced this induction (Fig. 9C, densitometrically quantified below). Although the physical separation of LC3-I from LC3-II by SDSPAGE gels in HeLa cells is robust, it is less prominent in studies of NSC-34 cells and primary neurons, as described prevously (Hetz et al., 2009). Efforts to enhance the physical separation of LC3-I from LC3-II using larger gels or gradient gels failed despite significant effort. This is a limitation of the study LC3 protein chemistry inherent to our primary neuron culture system. Together, these observations suggest that secinH 3 stimulates steps in the autophagy process. Because this is detectable in the presence of mutant SOD1, it raises the possibility that the neuroprotective actions of secinH3 are linked to autophagy induction.

The steady-state level of LC3-II or p62 does not report autophagic flux and a number of different assays have been proposed to overcome this limitation (Mizushima et al., 2010). The difference in LC3-II levels with or without inhibition of lysosomal protein degradation can be used to measure autophagic flux. We treated HeLa cells with $50 \mu \mathrm{m}$ secinH3 or vehicle and then inhibited autophagy with the vaculoar $\mathrm{H}^{+}$-ATPase inhibitor Baf A1. Western blots of LC3 show that secinH3 enhances the difference between LC3-II levels in the presence versus absense of Baf A1 (when normalized to actin; Fig. 9D, densitometrically quantified below). Similarly, secinH3 enhances the difference between p62 levels in the prescence versus absence of Baf A1. The same basic observations are seen using a different autophagy inhibitor, 3-MA (data not shown). These observations suggest that secinH3 stimulates autophagic flux.

\section{SecinH3 enhances the clearance of mutant SOD1}

In the context of neurodegenerative disorders, a consensus is emerging that the induction of autophagy can be a neuroprotective response (Levine and Kroemer, 2008; Mizushima et al., 2008; Metcalf et al., 2012; Choi et al., 2013). Promoting the clearance of aggregate-prone proteins via induction of autophagy has proven to be a useful mechanism for protecting against the toxic effects of these proteins. In light of the observation that secinH3 was neuroprotective, reduced ER stress, and stimulated autophagic flux, we next determined the effects of secinH3 on the accumulation of mutant SOD. We began with stable and inducible motor-neuron-like NSC34 cells expressing EGFP-tagged WT SOD1 or G93A mutant SOD1 (Mali and Zisapels, 2008). In these cells, the transgene expression can be induced by adding doxycycline (Fig. 10A) and then switched off by removing doxycycline from the medium.

We then investigated the effects of secinH 3 treatment on the clearance of soluble G93A mutant SOD1 protein. NSC34 cells expressing G93A SOD1 were cultured in the presence of doxycycline for $24 \mathrm{~h}$ to induce the expression of mutant SOD1. After four washes with PBS to remove doxycycline, cells were incubated with fresh medium with $50 \mu \mathrm{M}$ secinH 3 and then treated every other day thereafter as needed or given vehicle. At 24, 48, and $60 \mathrm{~h}$ after the removal of doxycycline, Western blotting did 
A

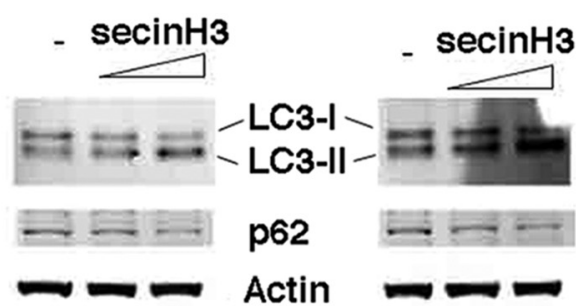

No starvation
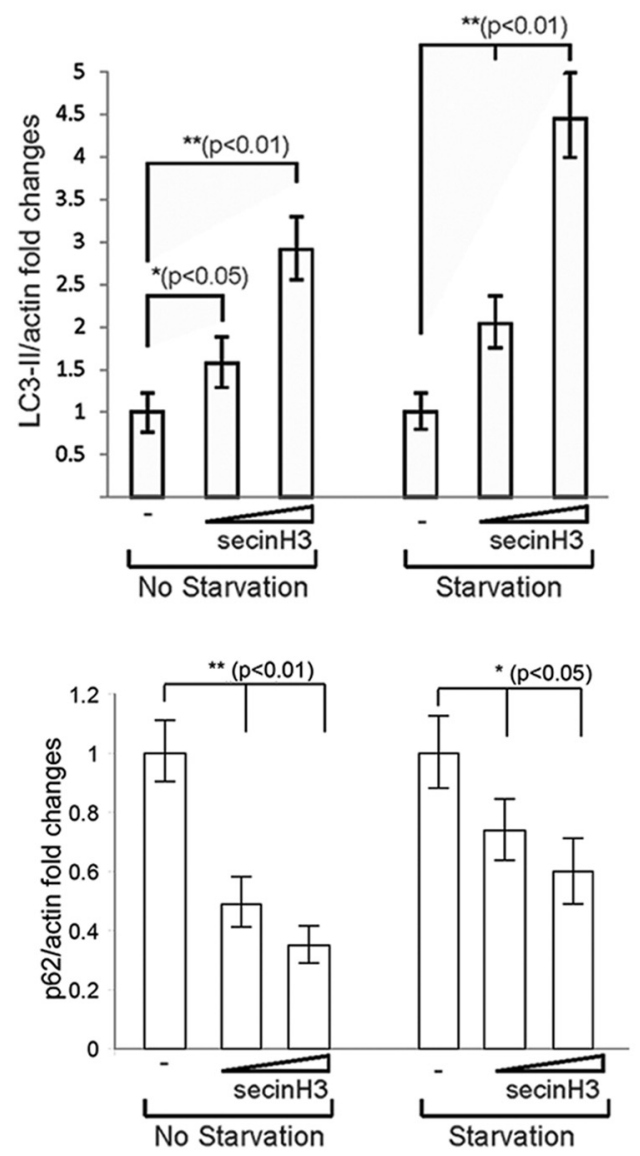

B

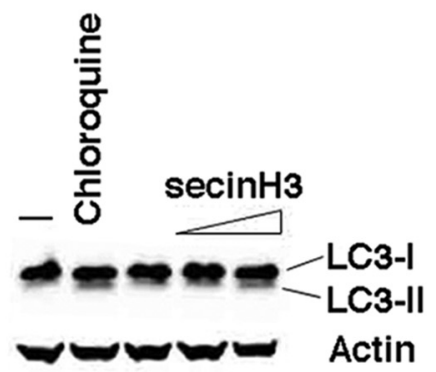

C
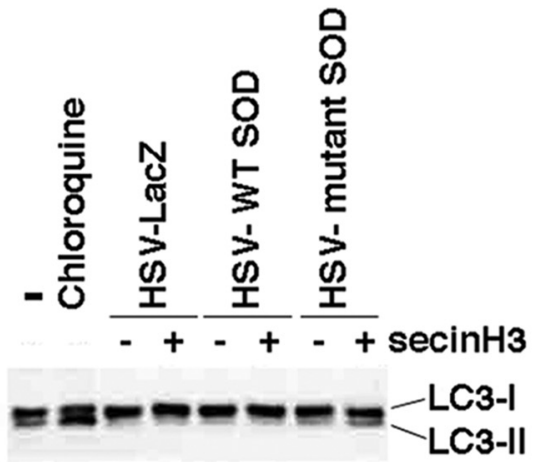

$=-\infty-\infty-1$ Actin

HEK $1^{\circ}$ Neurons

293

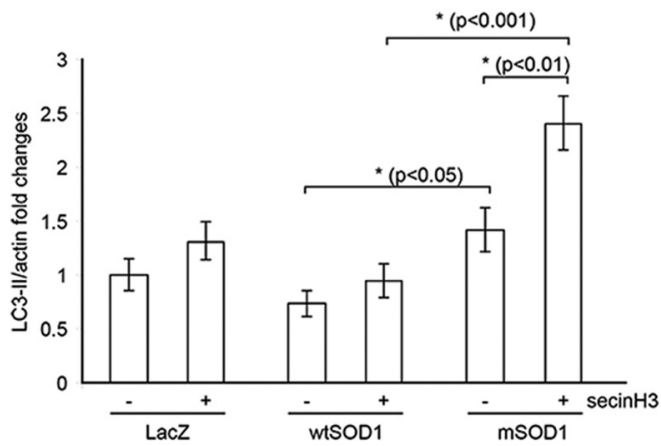

D

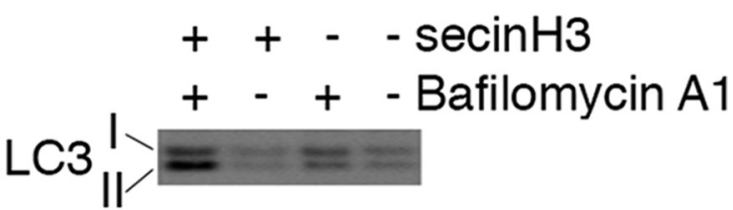

p62 - - - -

Actin - - -

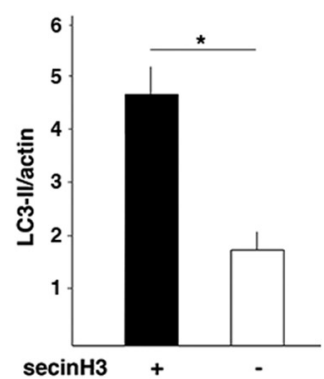

Figure 9. HeLa cells and neurons treated with secinH3 display biochemical signs of enhanced autophagy. Starved or unstarved HeLa cells were treated for $24 \mathrm{~h}$ with increasing dose of secinH3 ( 0 , $17,50 \mu \mathrm{m})$ and lysates were prepared for biochemistry. $A$, SecinH3 leads to a dose-dependent increase in LC3-II levels in starved or unstarved HeLa cells and this is associated with falling levels of p62. This effect is more marked in starved cells. Quantification of band intensities is shown below the Western blots. B, SecinH3 leads to a dose-dependent increase in LC3-II levels in primary spinal cord neurons. Separation of the LC3-I from the LC3-II band is not as robust using neuron lysates as it is using HeLa cell lysates. The authencity of the LC3-II band is confirmed by treating neurons with the autophagy inhibitor chloroquine. C, Primary neurons expressing mutant SOD (but not WT SOD or LacZ) and treated with secinH3 (50 $\mu \mathrm{M})$ show an increase in LC3-IIl levels compared with vehicle treated cells. Quantification of induction of LC3-II levels (normalized to actin) is shown in the bar graphs below the Western blots. D, The ratio of LC3-II/actin in Baf A1-treated cells versus vehicle-treated cells is a measure of autophagic flux. This ratio is greater in secinH3 $(50 \mu \mathrm{m})$-treated versus vehicle-treated HeLa cells. This indicates that secinH3 stimulates autophagic flux. Quantification of autophagic flux induction by secinH3 is shown below the Western blots. 
A
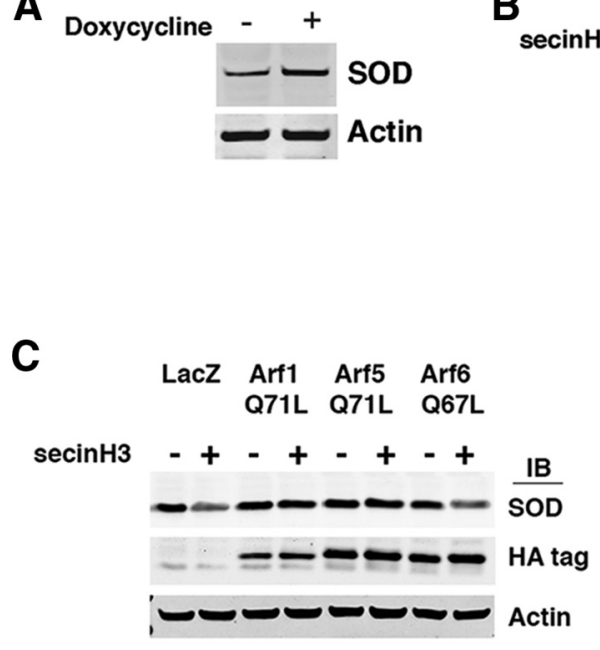

B
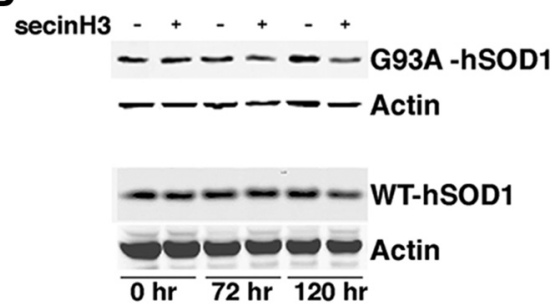

D

$\begin{aligned} & \operatorname{secinH} 3- \pm \text { SOD (misfolded) } \\ &- \text { SOD (sol) } \\ &- \text { SOD (sol) } \\ &- \text { Actin } \\ &=- \text { SOD (insol) } \\ &-- \text { Actin }\end{aligned}$

Figure 10. SecinH3 stimulates degradation of mutant and WT SOD in pulse-chase experiments using NSC-34 cells; the effect is ARF dependent and this leads to reduced burden of soluble and misfolded SOD. Stable cell lines engineered to inducibly express WT or mutant SOD were studied. $\boldsymbol{A}$, Doxycycline treatment of NSC-34-mutant SOD cells induces SOD expression. $\boldsymbol{B}$, After a pulse of doxycycline, there is a progressive loss of mutant SOD expression by NSC-34 cells and treatment of cells with $50 \mu \mathrm{m}$ secinH 3 during the chase period enhances mutant SOD degradation at the $120 \mathrm{~h}$ time point (top). The same phenomenon occurs with NSC-34 cells engineered to inducibly express WT SOD (bottom). C, The ability of secinH3 (50 $\mu \mathrm{m})$ to accelerate degradation of mutant SOD is blocked by expressing constitutively active ARF1 (Q71L) or ARF5 (Q71L), but not ARF6 (Q67L) or LacZ, indicating that inhibition of ARF activation is how secinH3 stimulates mutant SOD degradation. Expression levels of $\mathrm{HA}$ tagged ARF constructs are not affected by secinH3 treatment (HA tagged Western blots). $\boldsymbol{D}$, Lysates from mutant SOD-expressing NSC-34 cells ( \pm secinH3 $50 \mu \mathrm{M}$ treatment) were obtained $120 \mathrm{~h}$ after a doxycycline pulse and fractionated. Treatment with secinH3 reduced the abundance of misfolded and soluble SOD.

not show dramatic differences in the abundance of G93A SOD1 proteins in cells treated with secinH3 compared with vehicle treatment (data not shown). We found that the abundance of G93A SOD1 decreased in cells treated with secinH3 at 72 and $120 \mathrm{~h}$ after doxycycline removal (Fig. 10B, top). These data suggest that inhibition of cytohesin signaling with secinH3 enhances the clearance of soluble mutant SOD1 proteins, probably by augmentation of autophagy.

To determine whether this effect was restricted to mutant SOD, we studied a second NSC34-stable cell line that was engineered to express WT SOD. We followed the same protocol described above and found that secinH3 had no effect on the abundance of WT SOD up to $72 \mathrm{~h}$ after withdrawal of doxycline. At the $120 \mathrm{~h}$ time point, cells treated with secinH3 had less WT SOD compared with vehicle-treated cells (Fig. 10B, bottom). Together, these results suggest that secin $\mathrm{H} 3$ accelerates the degradation of both mutant and WT SOD in this inducible expression system; the effect on mutant SOD degradation appears to be more robust.

We attempted to rescue the secinH3 effect on SOD degradation by transfecting noninhibitable, constitutively active ARFs into G93A mutant SOD-expressing NSC34 cells and treating with secinH3 or vehicle. NSC34 cells were transfected with expression plasmids for Q71L ARF1 or Q71L ARF5 or Q67L ARF6 or LacZ, transiently stimulated with doxycycline, and incubated with secinH3 or vehicle for $120 \mathrm{~h}$ before lysates were prepared and immunoblotted for SOD or the HA-tagged ARF constructs. SecinH3 led to enhanced degradation of SOD in LacZtransfected cells. Interestingly, the expression of Q71L ARF1 or Q71L ARF5, but not Q67L ARF6, blocked the secinH3 effect on mutant SOD expression (Fig. 10C). All of the constitutively active ARFs were expressed at similar levels in cells. We draw two con-

clusions from these results. First, the enhanced degradation of mutant SOD by secinH3 is likely to be mediated by inhibition of cytohesin activity because constitutive activity of their downstream targets (ARFs) overcomes the drug effect. Second, ARF1- and ARF5-mediated events may be particularly relevant to the clearance of mutant SOD because only these constitutively active mutants ablated the secinH3 effect.

Up to this point, we had only studied the effects of secinH3 on the abundance of the Triton-X 100-soluble pool of mutant SOD. We next investigated whether secinH3 alters the abundance of a misfolded version of SOD (detectable by immunoprecipitation with the MS785; Fujisawa et al., 2012), as well as soluble versus insoluble SOD. G93A mutant SOD NSC34 cells were pulsed with doxycycline and incubated with $50 \mu \mathrm{M}$ secinH3 and then treated every other day thereafter or with vehicle for $120 \mathrm{~h}$. Lysates were prepared and aliquots of the starting material obtained and subjected to Western blot for soluble SOD. The volume of lysate for immunoprecipiation with the MS785 antibody was adjusted so that equal amounts of soluble SOD were present in the two samples. When analyzed in this way, we found a decrease in misfolded SOD in the secinH3- versus vehicle-treated cells, whereas the starting amount of soluble SOD was, as designed, equivalent in the two samples (Fig. 10D). In a parallel set of dishes, we compared Triton X-100-soluble versus -insoluble mutant SOD from cells treated with secinH3 or vehicle for $120 \mathrm{~h}$. SecinH3 led to a decrease in soluble SOD (normalized to actin), but not insoluble SOD (Fig. 10D). These results suggest that secinH3 treatment accelerates the degradation of misfolded SOD. Because misfolded SOD is likely to be in thermodynamic equilibrium with properly folded SOD, the enhanced degradation of misfolded SOD may also lead to a reduction in the steadystate levels of properly folded SOD. The lack of effect of secinH3 on Triton X-100-insoluble SOD samples suggests that this pool is more stable in NSC-34 cells under these experimental conditions.

Finally, we investigated whether reducing cytohesin function in primary neurons expressing mutant SOD influenced the abundance of misfolded soluble and insoluble SOD levels. Primary neuronal cultures were infected with HSV-G85R SOD and treated for $3 \mathrm{~d}$ with secinH3 (50 $\mu \mathrm{M}$ and every other day thereafter as needed) or vehicle before lysates were prepared for Western blot. Previous work has demonstrated that no neuronal death occurs at this time point in this experimental paradigm (Mojsilovic-Petrovic et al., 2006). Treatment with secinH3 reduced the neuronal abundance of misfolded soluble and insoluble SOD (Fig. 11A,C). The level of actin is the same in these experimental groups, in further support of the notion that neuronal death is not the reason for the secinH3-dependent changes in SOD abundance.

To consolidate these observations, we investigated whether knock-down of cytohesin in neurons expressing mutant SOD influenced the abundance of misfolded soluble and insoluble SOD. Primary neuronal cultures were infected with HSV-G85R SOD and the pan-Cy miRNA (or the scrambled sequence con- 
A secinH3 - + $\leadsto-$ SOD (misfolded) - SOD (sol) $==$ Actin - SOD (insol) - Actin

B

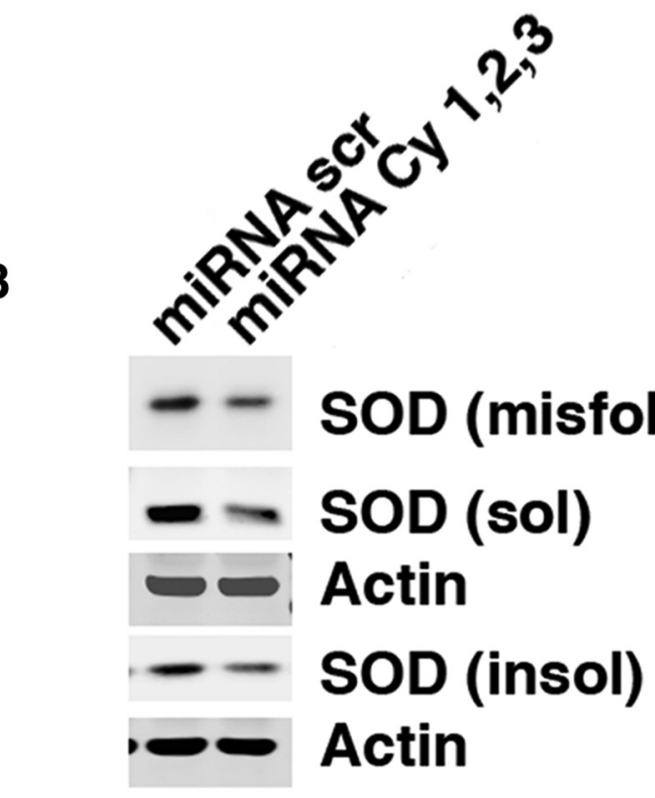

C

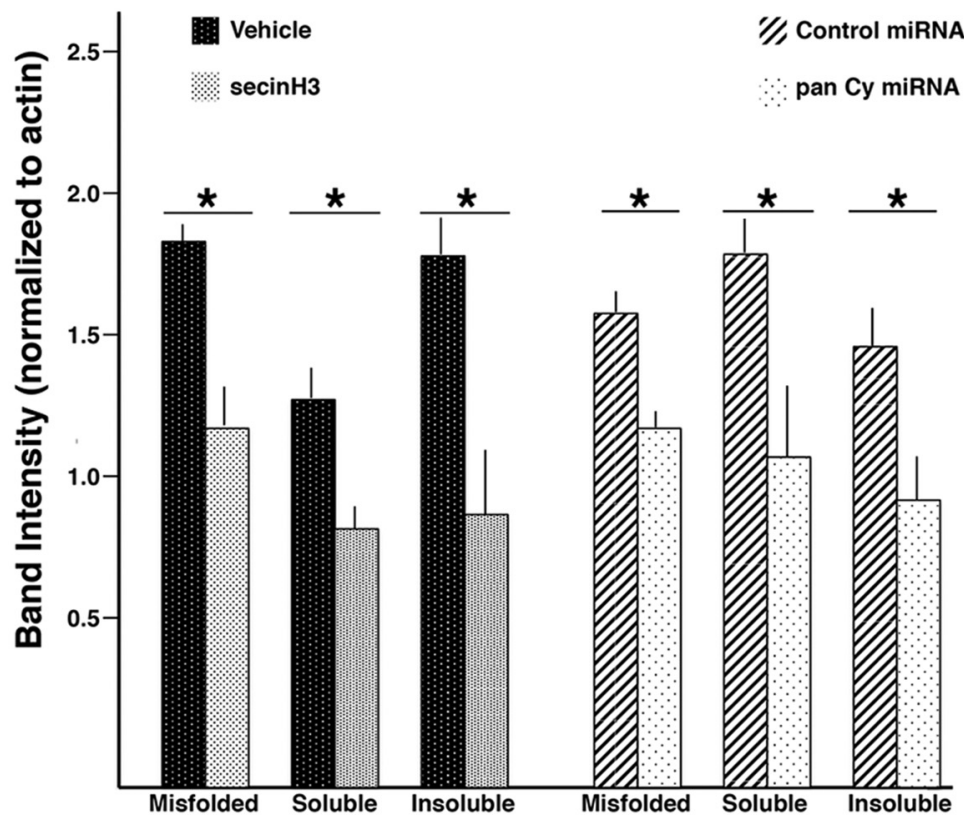

SOD Species trol) and, 3 d later, lysates were prepared for Western blot. Knock-down of Cyl, $\mathrm{Cy} 2$, and $\mathrm{Cy} 3$ reduced the neuronal abundance of misfolded soluble and insoluble SOD without influencing the abundance of actin (Fig. $11 \mathrm{~B}, \mathrm{C}$ ). These observations indicate that pharmacological or genetic reduction in cytohesin activity, either in cell lines or primary neurons, reduces the burden of toxic forms of mutant SOD.

\section{Discussion}

Cytohesins are a group of proteins composed of conserved N-terminal coiledcoil, central Sec7, and C-terminal PH domains. They have emerged as versatile regulators of cellular signaling transduction and vesicle traffic, controlling cell growth and proliferation, differentiation, and migration (Nie et al., 2003; Randazzo and Hirsch, 2004; Casanova, 2007; Donaldson and Jackson, 2011). In the present study, we found that pharmacological or genetic inhibition of cytohesin activity combats the toxic activity of diseaselinked mutant proteins in both in vitro and in vivo model systems. The beneficial actions of cytohesin antagonism are linked to their ability to attenuate ER stress and promote autophagy. The development of orally active, blood-brain barrier-permeable cytohesin activity inhibitors might benefit neurodegenerative diseases with impaired protein homeostasis.

Activation of the UPR upon ER stress is the earliest detectable event in the pathophysiology of mutant SOD toxicity in neurons (Saxena et al., 2009) and there is evidence for UPR activation in many neurodegenerative disease models (Ryoo et al., 2007; Urushitani et al., 2008; Wang et al., 2011; Colla et al., 2012a; Colla et al., 2012b; Abisambra et al., 2013; Vaccaro et al., 2013). Activated UPR can have beneficial and noxious effects on neurons and the balance between these outcomes is

Figure 11. Reducing cytohesin activity with secinH3 or abundance with pan-Cy miRNA in primary spinal cord neurons reduces the burden of misfolded, soluble, and insoluble SOD. DIV 14 spinal cord neurons were infected with HSV-mut SOD and treated with secinH 3 or vehicle for $3 \mathrm{~d}$. In a parallel set of cultures, mutant SOD-expressing cells were simultaneously infected with HSV engineered to express pan-Cy miRNA to knock down Cy1, Cy2, and Cy3 or a scrambled miRNA for $3 \mathrm{~d}$. Lysates were fractionated and subjected to Western blot. $\boldsymbol{A}$, secinH3 $(50 \mu \mathrm{m})$ treatment leads to decreased abundance of misfolded soluble and insoluble SOD in neurons expressing mutant SOD. B, Knock-down of Cy1, Cy2, and Cy3 leads to decreased abundance of misfolded, soluble, and insoluble SOD in neurons expressing mutant SOD. C, Quantification of Western blot data showing statistically significant group differences (Student's $t$ test, ${ }^{*} p<0.05$ ). 
likely determined by the duration/level of UPR activation (Walter and Ron, 2011). Disposal of misfolded and aggregated proteins is essential for restoration of protein homeostasis, and this is accomplished in part through the ubiquitin-proteasomal system and autophagy. Blocking cytohesin activity alleviates ER stress by stimulating autophagic flux and this is likely to be the root cause for the beneficial actions that we describe in our various models of neurodegeneration. This is consistent with the observation that a variety of pharmacological stimulators of autophagy also confer benefit in models of neurodegenerative disease (Ravikumar et al., 2004; Zhang et al., 2007; Fornai et al., 2008; Wang et al., 2012; but see Zhang et al., 2011 and Yu et al., 2005).

Mutant SOD has been shown to bind to a variety of proteins (e.g., Derlin1, Nishitoh et al., 2008; VDAC, Israelson et al., 2010; Bcl2, Pasinelli et al., 2004; Tan et al., 2013; cytosolic malate dehydrogenase, Mali and Zisapels, 2008) and to influence their function. As a function of these protein-protein interactions, evidence has accrued for mutant SOD to: (1) disrupt retrotranslocation, impair ER associated degradation, and evoke ER stress; (2) reduce VDAC channel activity and mitochondrial ADP uptake; (3) bind to and sequester the anti-apoptotic factor Bcl-2; and (4) rewire cellular metabolism with inhibition of the malateaspartate shuttle and enhancement of lactate production to maintain $\mathrm{NADH} / \mathrm{NAD}^{+}$levels. Adding to this list, we demonstrate here that cytohesins bind mutant SOD, particularly as part of a SOD-SOD dimer. Despite this interaction, we are unable to demonstrate an effect of mutant SOD on cytohesin 2 GEF activity or the cellular levels of GTP-bound ARF6. Although these observations may be interpreted to indicate that the association of $\mathrm{SOD}$ with cytohesins does not affect their ARF GEF activity, we urge caution. First, in vitro conditions used to assay GEF activity are only an approximation of the complex regulatory environment within cells. Second, our cell-based biochemical approach assesses aggregate activity of ARF GEFs; differences in the activity of ARF GEF activity within specific subcellular domains would not be resolved by this approach. A recent study shows that the abundance of GTP-bound ARFs at focal adhesions can differ substantially from the total pool assayed by GTP-bound ARF pulldown assays (Chen et al., 2013). Third, GTP-bound ARF6 pulldown studies require overexpression of a tagged version of ARF6 and thus may not faithfully report changes in the state of endogenous ARFs. Higher-resolution work will be needed to determine the functional consequences of the SOD-cytohesin complexes we identify here.

Recent work has highlighted the participation of membranetrafficking small GTPases (e.g., RAB, ARF, and RALB subfamilies) in the regulation of autophagy (Bento et al., 2013). ARF6 promotes the formation of early autophagosomes through the production of phosphatidylinosital 4,5-biphosphate $\left(\mathrm{PIP}_{2)}\right.$ and stimulation of phospholipase D activity (Moreau et al., 2012). $\mathrm{PIP}_{2}$ has also been shown to play a key role in initiating fission/ budding of protolysosomes from reformation tubules (Rong et al., 2012). ARF1 can inhibit the negative regulator of autophagy TORC1 (Li et al., 2010). ARF1 and ARF2 are needed for the mobilization of membranes from the Golgi complex in the process of expanding the phagophore into an autophagosome (van der Vaart et al., 2010). Many of these ARF-mediated actions would be predicted to stimulate autophagic flux. Conversely, cytohesin 2 is recruited to V-ATPase a2-subunit (a2N) in an acidification-dependent manner and a2N potently inhibits cytohesin GEF activity (Hosokawa et al., 2013). V-ATPases are important for endosome carrier vesicle maturation and contribute to acidic pH of lysosomes (Hurtado-Lorenzo et al., 2006). GEF inhibition may regulate V-ATPase activity and contribute to autophagic capacity (Hosokawa et al., 2013; Marshansky and Futai, 2008). In addition to these activities, ARFs and ARF GAPs (GTPase activating proteins) can participate in RAB GTPasemediated processes (Frasa et al., 2010; Egami et al., 2011; Dong et al., 2012). As noted above, RAB GTPases play a key regulatory role in several steps in the autophagy process. Because most research has focused on the role of single cytohesins or single ARFs, we lack a comprehensive understanding of the impact of these proteins in such a complex process as autophagy. Our observations suggest that the net effect of cytohesin inhibition is to enhance autophagic flux. The precise steps that tip the balance in favor of increased autophagy within this interconnected regulatory network remain to be defined.

\section{References}

Abisambra JF, Jinwal UK, Blair LJ, O’Leary JC 3rd, Li Q, Brady S, Wang L, Guidi CE, Zhang B, Nordhues BA, Cockman M, Suntharalingham A, Li P, Jin Y, Atkins CA, Dickey CA (2013) Tau accumulation activates the unfolded protein response by impairing endoplasmic reticulum-associated degradation. J Neurosci 33:9498-9507. CrossRef Medline

Al-Chalabi A, Hardiman O (2013) The epidemiology of ALS: a conspiracy of genes, environment and time. Nat Rev Neurol 9:617-628. CrossRef Medline

Bento CF, Puri C, Moreau K, Rubinsztein DC (2013) The role of membrane-trafficking small GTPases in the regulation of autophagy. J Cell Sci 126:1059-1069. CrossRef Medline

Bjørkøy G, Lamark T, Brech A, Outzen H, Perander M, Overvatn A, Stenmark $\mathrm{H}$, Johansen T (2005) p62/SQSTM1 forms protein aggregates degraded by autophagy and has a protective effect on huntingtin-induced cell death. J Cell Biol 171:603-614. CrossRef Medline

Brenner S (1974) The genetics of Caenorhabditis elegans. Genetics 77:71-94. Medline

Calixto A, Chelur D, Topalidou I, Chen X, Chalfie M (2010) Enhanced neuronal RNAi in C. elegans using SID-1. Nat Methods 7:554-559. CrossRef Medline

Casanova JE (2007) Regulation of Arf activation: the Sec7 family of guanine nucleotide exchange factors. Traffic 8:1476-1485. CrossRef Medline

Cermak T, Doyle EL, Christian M, Wang L, Zhang Y, Schmidt C, Baller JA, Somia NV, Bogdanove AJ, Voytas DF (2011) Efficient design and assembly of custom TALEN and other TAL effector-based constructs for DNA targeting. Nucleic Acids Res 39:e82. CrossRef Medline

Chen PW, Jian X, Yoon HY, Randazzo PA (2013) ARAP2 signals through Arf6 and Rac1 to control focal adhesion morphology. J Biol Chem 288: 5849-5860. CrossRef Medline

Choi AM, Ryter SW, Levine B (2013) Autophagy in human health and disease. N Engl J Med 368:651-662. CrossRef Medline

Cleveland DW, Rothstein JD (2001) From Charcot to Lou Gehrig: deciphering selective motor neuron death in ALS. Nat Rev Neurosci 2:806819. CrossRef Medline

Colla E, Jensen PH, Pletnikova O, Troncoso JC, Glabe C, Lee MK (2012a) Accumulation of toxic alpha-synuclein oligomer within endoplasmic reticulum occurs in alpha-synucleinopathy in vivo. J Neurosci 32:33013305. CrossRef Medline

Colla E, Coune P, Liu Y, Pletnikova O, Troncoso JC, Iwatsubo T, Schneider BL, Lee MK (2012b) Endoplasmic reticulum stress is important for the manifestations of alpha-synucleinopathy in vivo. J Neurosci 32:33063320. CrossRef Medline

Donaldson JG, Jackson CL (2011) ARF family G proteins and their regulators: roles in membrane transport, development and disease. Nat Rev Mol Cell Biol 12:362-375. CrossRef Medline

Dong N, Zhu Y, Lu Q, Hu L, Zheng Y, Shao F (2012) Structurally distinct bacterial TBC-like GAPs link Arf GTPase to Rab1 inactivation to counteract host defenses. Cell 150:1029-1041. CrossRef Medline

D'Souza-Schorey C, Chavrier P (2006) ARF proteins: roles in membrane traffic and beyond. Nat Rev Mol Cell Biol 7:347-358. Medline

Egami Y, Fukuda M, Araki N (2011) Rab35 regulates phagosome formation through recruitment of ACAP2 in macrophages during FcgammaRmediated phagocytosis. J Cell Sci 124:3557-3567. CrossRef Medline

Feigenson K, Reid M, See J, Crenshaw III EB, Grinspan JB (2011) Canonical 
Wnt signaling requires the BMP pathway to inhibit oligodendrocyte maturation. ASN NEURO 3:e00061. Medline

Ferraiuolo L, Kirby J, Grierson AJ, Sendtner M, Shaw PJ (2011) Molecular pathways of motor neuron injury in amyotrophic lateral sclerosis. Nat Rev Neurol 7:616-630. CrossRef Medline

Fornai F, Longone P, Cafaro L, Kastsiuchenka O, Ferrucci M, Manca ML, Lazzeri G, Spalloni A, Bellio N, Lenzi P, Modugno N, Siciliano G, Isidoro C, Murri L, Ruggieri S, Paparelli A (2008) Lithium delays progression of amyotrophic lateral sclerosis. Proc Natl Acad Sci U S A 105:2052-2057. CrossRef Medline

Frasa MA, Maximiano FC, Smolarczyk K, Francis RE, Betson ME, Lozano E, Goldenring J, Seabra MC, Rak A, Ahmadian MR, Braga VM (2010) Armus is a Racl effector that inactivates Rab7 and regulates E-cadherin degradation. Curr Biol 20:198-208. CrossRef Medline

Fujisawa T, Homma K, Yamaguchi N, Kadowaki H, Tsuburaya N, Naguro I, Matsuzawa A, Takeda K, Takahashi Y, Goto J, Nishitoh H, Ichijo H (2012) A novel monoclonal antibody reveals a conformational alteration shared by amyotrophic lateral sclerosis-linked SOD1 mutants. Ann Neurol 72:739-749. CrossRef Medline

Ha VL, Thomas GM, Stauffer S, Randazzo PA (2005) Preparation of myristoylated Arf1 and Arf6. Methods Enzymol 404:164-174. CrossRef Medline

Hafner M, Schmitz A, Grüne I, Srivatsan SG, Paul B, Kolanus W, Quast T, Kremmer E, Bauer I, Famulok M (2006) Inhibition of cytohesins by SecinH3 leads to hepatic insulin resistance. Nature 444:941-944. CrossRef Medline

Hetz C, Thielen P, Matus S, Nassif M, Court F, Kiffin R, Martinez G, Cuervo AM, Brown RH, Glimcher LH (2009) XBP-1 deficiency in the nervous system protects against amyotrophic lateral sclerosis by increasing autophagy. Genes Dev 23:2294-2306. Medline

Hosokawa H, Dip PV, Merkulova M, Bakulina A, Zhuang Z, Khatri A, Jian X, Keating SM, Bueler SA, Rubinstein JL, Randazzo PA, Ausiello DA, Grüber G, Marshansky V (2013) The $\mathrm{N}$ termini of a-subunit isoforms are involved in signaling between vacuolar $\mathrm{H}+$-ATPase (V-ATPase) and cytohesin-2. J Biol Chem 288:5896-5913. CrossRef Medline

Hurtado-Lorenzo A, Skinner M, El Annan J, Futai M, Sun-Wada GH, Bourgoin S, Casanova J, Wildeman A, Bechoua S, Ausiello DA, Brown D, Marshansky V (2006) V-ATPase interacts with ARNO and Arf6 in early endosomes and regulates the protein degradative pathway. Nat Cell Biol 8:124-136. CrossRef Medline

Israelson A, Arbel N, Da Cruz S, Ilieva H, Yamanaka K, Shoshan-Barmatz V, Cleveland DW (2010) Misfolded mutant SOD1 directly inhibits VDAC1 conductance in a mouse model of inherited ALS. Neuron 67:575587. CrossRef Medline

Jeong GB, Mojsilovic-Petrovic J, Boccitto M, Kalb R (2011) Signaling events in axons and/or dendrites render motor neurons vulnerable to mutant superoxide dismutase toxicity. J Neurosci 31:295-299. CrossRef Medline

Jian X, Cavenagh M, Gruschus JM, Randazzo PA, Kahn RA (2010) Modifications to the C-terminus of Arf1 alter cell functions and protein interactions. Traffic 11:732-742. CrossRef Medline

Jian X, Gruschus JM, Sztul E, Randazzo PA (2012) The pleckstrin homology (PH) domain of the Arf exchange factor Brag2 is an allosteric binding site. J Biol Chem 287:24273-24283. CrossRef Medline

Levine B, Kroemer G (2008) Autophagy in the pathogenesis of disease. Cell 132:27-42. CrossRef Medline

Li L, Kim E, Yuan H, Inoki K, Goraksha-Hicks P, Schiesher RL, Neufeld TP, Guan KL (2010) Regulation of mTORC1 by the Rab and Arf GTPases. J Biol Chem 285:19705-19709. CrossRef Medline

Lim MA, Selak MA, Xiang Z, Krainc D, Neve RL, Kraemer BC, Watts JL, Kalb RG (2012) Reduced activity of AMP-activated protein kinase protects against genetic models of motor neuron disease. J Neurosci 32:11231141. CrossRef Medline

Ling SC, Polymenidou M, Cleveland DW (2013) Converging mechanisms in ALS and FTD: disrupted RNA and protein homeostasis. Neuron 79: 416-438. CrossRef Medline

Lo TW, Pickle CS, Lin S, Ralston EJ, Gurling M, Schartner CM, Bian Q, Doudna JA, Meyer BJ (2013) Precise and heritable genome editing in evolutionarily diverse nematodes using TALENs and CRISPR/Cas9 to engineer insertions and deletions. Genetics 195:331-348. CrossRef Medline

Mali Y, Zisapels N (2008) Gain of interaction of ALS-linked G93A superox- ide dismutase with cytosolic malate dehydrogenase. Neurobiol Dis 32: 133-141. CrossRef Medline

Marshansky V, Futai M (2008) The V-type H+-ATPase in vesicular trafficking: targeting, regulation and function. Curr Opin Cell Biol 20:415426. CrossRef Medline

Metcalf DJ, García-Arencibia M, Hochfeld WE, Rubinsztein DC (2012) Autophagy and misfolded proteins in neurodegeneration. Exp Neurol 238: 22-28. CrossRef Medline

Mizushima N, Levine B, Cuervo AM, Klionsky DJ (2008) Autophagy fights disease through cellular self-digestion. Nature 451:1069-1075. CrossRef Medline

Mizushima N, Yoshimori T, Levine B (2010) Methods in mammalian autophagy research. Cell 140:313-326. CrossRef Medline

Mojsilovic-Petrovic J, Jeong GB, Crocker A, Arneja A, David S, Russell DS, Russell D, Kalb RG (2006) Protecting motor neurons from toxic insult by antagonism of adenosine A2a and Trk receptors. J Neurosci 26:9250 9263. CrossRef Medline

Mojsilovic-Petrovic J, Nedelsky N, Boccitto M, Mano I, Georgiades SN, Zhou W, Liu Y, Neve RL, Taylor JP, Driscoll M, Clardy J, Merry D, Kalb RG (2009) FOXO3a is broadly neuroprotective in vitro and in vivo against insults implicated in motor neuron diseases. J Neurosci 29:8236-8247. CrossRef Medline

Moreau K, Ravikumar B, Puri C, Rubinsztein DC (2012) Arf6 promotes autophagosome formation via effects on phosphatidylinositol 4,5bisphosphate and phospholipase D. J Cell Biol 196:483-496. CrossRef Medline

Nie Z, Hirsch DS, Randazzo PA (2003) Arf and its many interactors. Curr Opin Cell Biol 15:396-404. CrossRef Medline

Nishitoh H, Kadowaki H, Nagai A, Maruyama T, Yokota T, Fukutomi H, Noguchi T, Matsuzawa A, Takeda K, Ichijo H (2008) ALS-linked mutant SOD1 induces ER stress- and ASK1-dependent motor neuron death by targeting Derlin-1. Genes Dev 22:1451-1464. CrossRef Medline

Pasinelli P, Belford ME, Lennon N, Bacskai BJ, Hyman BT, Trotti D, Brown RH Jr (2004) Amyotrophic lateral sclerosis-associated SOD1 mutant proteins bind and aggregate with Bcl-2 in spinal cord mitochondria. Neuron 43:19-30. CrossRef Medline

Perlson E, Jeong GB, Ross JL, Dixit R, Wallace KE, Kalb RG, Holzbaur EL (2009) A switch in retrograde signaling from survival to stress in rapidonset neurodegeneration. J Neurosci 29:9903-9917. CrossRef Medline

Popoff V, Langer JD, Reckmann I, Hellwig A, Kahn RA, Brügger B, Wieland FT (2011) Several ADP-ribosylation factor (Arf) isoforms support COPI vesicle formation. J Biol Chem 286:35634-35642. CrossRef Medline

Puls I, Jonnakuty C, LaMonte BH, Holzbaur EL, Tokito M, Mann E, Floeter MK, Bidus K, Drayna D, Oh SJ, Brown RH Jr, Ludlow CL, Fischbeck KH (2003) Mutant dynactin in motor neuron disease. Nat Genet 33:455456. CrossRef Medline

Radhakrishna H, Donaldson JG (1997) ADP-ribosylation factor 6 regulates a novel plasma membrane recycling pathway. J Cell Biol 139:49-61. CrossRef Medline

Randazzo PA, Hirsch DS (2004) Arf GAPs: multifunctional proteins that regulate membrane traffic and actin remodelling. Cell Signal 16:401-413. CrossRef Medline

Randazzo PA, Terui T, Sturch S, Fales HM, Ferrige AG, Kahn RA (1995) The myristoylated amino terminus of ADP-ribosylation factor 1 is a phospholipid- and GTP-sensitive switch. J Biol Chem 270:14809-14815. CrossRef Medline

Ravikumar B, Vacher C, Berger Z, Davies JE, Luo S, Oroz LG, Scaravilli F, Easton DF, Duden R, O'Kane CJ, Rubinsztein DC (2004) Inhibition of mTOR induces autophagy and reduces toxicity of polyglutamine expansions in fly and mouse models of Huntington disease. Nat Genet 36:585595. CrossRef Medline

Rong Y, Liu M, Ma L, Du W, Zhang H, Tian Y, Cao Z, Li Y, Ren H, Zhang C, Li L, Chen S, Xi J, Yu L (2012) Clathrin and phosphatidylinositol-4,5bisphosphate regulate autophagic lysosome reformation. Nat Cell Biol 14:924-934. CrossRef Medline

Rosen DR, Siddique T, Patterson D, Figlewicz DA, Sapp P, Hentati A, Donaldson D, Goto J, O’Regan JP, Deng HX, Rahmani Z, Krizus A, McKennaYasek D, Cayabyab A, Gaston SM, Berger R, Tanzi RE, Halperin JJ, Herzfeldt B, Van den Berghet R, et al. (1993) Mutations in Cu/Zn superoxide dismutase gene are asociated with familial amyotrophic lateral sclerosis. Nature 362:59-62. CrossRef Medline 
Rothstein JD (2009) Current hypotheses for the underlying biology of amyotrophic lateral sclerosis. Ann Neurol 65:S3-S9. CrossRef Medline

Ryoo HD, Domingos PM, Kang MJ, Steller H (2007) Unfolded protein response in a Drosophila model for retinal degeneration. EMBO J 26:242252. CrossRef Medline

Saxena S, Cabuy E, Caroni P (2009) A role for motoneuron subtypeselective ER stress in disease manifestations of FALS mice. Nat Neurosci 12:627-636. CrossRef Medline

Shaw PJ (2005) Molecular and cellular pathways of neurodegeneration in motor neurone disease. J Neurol Neurosurg Psychiatry 76:1046-1057. CrossRef Medline

Shook SJ, Pioro EP (2009) Racing against the clock: recognizing, differentiating, diagnosing, and referring the amyotrophic lateral sclerosis patient. Ann Neurol 651:S10-S16. CrossRef Medline

Tan W, Naniche N, Bogush A, Pedrini S, Trotti D, Pasinelli P (2013) Small peptides against the mutant SOD1/Bcl-2 toxic mitochondrial complex restore mitochondrial function and cell viability in mutant SOD1mediated ALS. J Neurosci 33:11588-11598. CrossRef Medline

Urushitani M, Ezzi SA, Matsuo A, Tooyama I, Julien JP (2008) The endoplasmic reticulum-Golgi pathway is a target for translocation and aggregation of mutant superoxide dismutase linked to ALS. FASEB J 22:2476-2487. CrossRef Medline

Vaccaro A, Patten SA, Aggad D, Julien C, Maios C, Kabashi E, Drapeau P, Parker JA (2013) Pharmacological reduction of ER stress protects against TDP-43 neuronal toxicity in vivo. Neurobiol Dis 55:64-75. CrossRef Medline

van der Vaart A, Griffith J, Reggiori F (2010) Exit from the Golgi is required for the expansion of the autophagosomal phagophore in yeast Saccharomyces cerevisiae. Mol Biol Cell 21:2270-2284. CrossRef Medline

Volpicelli-Daley LA, Li Y, Zhang CJ, Kahn RA (2005) Isoform-selective effects of the depletion of ADP-ribosylation factors 1-5 on membrane traffic. Mol Biol Cell 16:4495-4508. CrossRef Medline

Walter P, Ron D (2011) The unfolded protein response: from stress pathway to homeostatic regulation. Science 334:1081-1086. CrossRef Medline

Wang IF, Guo BS, Liu YC, Wu CC, Yang CH, Tsai KJ, Shen CK (2012)
Autophagy activators rescue and alleviate pathogenesis of a mouse model with proteinopathies of the TAR DNA-binding protein 43. Proc Natl Acad Sci U S A 109:15024-15029. CrossRef Medline

Wang J, Farr GW, Hall DH, Li F, Furtak K, Dreier L, Horwich AL (2009) An ALS-linked mutant SOD1 produces a locomotor defect associated with aggregation and synaptic dysfunction when expressed in neurons of Caenorhabditis elegans. PLoS Genet 5:e1000350. CrossRef Medline

Wang L, Popko B, Roos RP (2011) The unfolded protein response in familial amyotrophic lateral sclerosis. Hum Mol Genet 20:1008-1015. CrossRef Medline

Wroe R, Wai-Ling Butler A, Andersen PM, Powell JF, Al-Chalabi A (2008) ALSOD: the Amyotrophic Lateral Sclerosis Online Database. Amyotroph Lateral Scler 9:249-250. CrossRef Medline

Yoon HY, Bonifacino JS, Randazzo PA (2005) In vitro assays of Arf1 interaction with GGA proteins. Methods Enzymol 404:316-332. CrossRef Medline

Yu WH, Cuervo AM, Kumar A, Peterhoff CM, Schmidt SD, Lee JH, Mohan PS, Mercken M, Farmery MR, Tjernberg LO, Jiang Y, Duff K, Uchiyama Y, Näslund J, Mathews PM, Cataldo AM, Nixon RA (2005) Macroautophagy-a novel Beta-amyloid peptide-generating pathway activated in Alzheimer's disease. J Cell Biol 171:87-98. CrossRef Medline

Zhai J, Lin H, Canete-Soler R, Schlaepfer WW (2005) HoxB2 binds mutant SOD1 and is altered in transgenic model of ALS. Hum Mol Genet 14: 2629-2640. CrossRef Medline

Zhang L, Yu J, Pan H, Hu P, Hao Y, Cai W, Zhu H, Yu AD, Xie X, Ma D, Yuan J (2007) Small molecule regulators of autophagy identified by an imagebased high-throughput screen. Proc Natl Acad Sci U S A 104:1902319028. CrossRef Medline

Zhang X, Li L, Chen S, Yang D, Wang Y, Zhang X, Wang Z, Le W (2011) Rapamycin treatment augments motor neuron degeneration in SOD1(G93A) mouse model of amyotrophic lateral sclerosis. Autophagy 7:412-425. CrossRef Medline

Zhang CJ, Rosenwald AG, Willingham MC, Skuntz S, Clark J, Kahn RA (1994) Expression of a dominant allele of human ARF1 inhibits membrane traffic in vivo. J Cell Biol 124:289-300. CrossRef Medline 